\title{
Swell and Slanting-Fetch Effects on Wind Wave Growth
}

\author{
Fabrice Ardhuin,* T. H. C. Herbers, ${ }^{+}$Gerbrant Ph. van Vledder, ${ }^{\#}$ Kristen P. Watts, ${ }^{+}, * *$ \\ R. JENSEN, ${ }^{@}$ AND HANS C. GRABER $\&$ \\ *Centre Militaire d'Océanographie, Service Hydrographique et Océanographique de la Marine, Brest, France \\ + Department of Oceanography, Naval Postgraduate School, Monterey, California \\ \# Alkyon Hydraulic Consultancy and Research, Emmeloord, Netherlands \\ ${ }^{\circledR}$ ERDC, U.S. Army Corps of Engineers, Vicksburg, Mississippi \\ ${ }^{\&}$ Division of Applied Marine Physics, Rosenstiel School of Marine and Atmospheric Science, University of Miami, \\ Coral Gables, Florida
}

(Manuscript received 19 November 2004, in final form 27 July 2006)

\begin{abstract}
Wind-sea generation was observed during two experiments off the coast of North Carolina. One event with offshore winds of 9-11 $\mathrm{m} \mathrm{s}^{-1}$ directed $20^{\circ}$ from shore normal was observed with eight directional stations recording simultaneously and spanning a fetch from 4 to $83 \mathrm{~km}$. An opposing swell of 1-m height and 10-s period was also present. The wind-sea part of the wave spectrum conforms to established growth curves for significant wave height and peak period, except at inner-shelf stations where a large alongshore wind-sea component was observed. At these short fetches, the mean wave direction $\theta_{m}$ was observed to change abruptly across the wind-sea spectral peak, from alongshore at lower frequencies to downwind at higher frequencies. Waves from another event with offshore winds of $6-14 \mathrm{~m} \mathrm{~s}^{-1}$ directed $20^{\circ}-30^{\circ}$ from shore normal were observed with two instrument arrays. A significant amount of low-frequency wave energy was observed to propagate alongshore from the region where the wind was strongest. These measurements are used to assess the performance of some widely used parameterizations in wave models. The modeled transition of $\theta_{m}$ across the wind-sea spectrum is smoother than that in the observations and is reproduced very differently by different parameterizations, giving insights into the appropriate level of dissipation. Calculations with the full Boltzmann integral of quartet wave-wave interactions reveal that the discrete interaction approximation parameterization for these interactions is reasonably accurate at the peak of the wind sea but overpredicts the directional spread at high frequencies. This error is well compensated by parameterizations of the wind input source term that have a narrow directional distribution. Observations also highlight deficiencies in some parameterizations of wave dissipation processes in mixed swell-wind-sea conditions.
\end{abstract}

\section{Introduction}

Wave forecasting and hindcasting is based on a large body of theory (e.g., Komen et al. 1994; Janssen 2004), which is often insufficient to fully account for complex flows near the ocean surface. For engineering purposes and to provide a benchmark for modeling wave growth, many studies have used dimensional analysis following

\footnotetext{
** Current affiliation: Directorate of Oceanography and Meteorology, Royal Australian Navy, Sydney, Australia.
}

Corresponding author address: Fabrice Ardhuin, Centre Militaire d'Océanographie, Service Hydrographique et Océanographique de la Marine, 29609 Brest, France.

E-mail: ardhuin@shom.fr
Kitaigorodskii (1962) and established empirical relations between the wave spectrum and the fetch or duration of wind forcing, water depth, and wind speed from a compilation of large datasets (e.g., Hasselmann et al. 1973; Bouws et al. 1985).

Scaling observed wave parameters with the acceleration of gravity $g$ and the wind speed $U_{10}$ (or the friction velocity $u_{*}$ ) allows quantitative comparison of wave growth observations in a wide range of situations, but there is still an order of magnitude variability in the observed wave energy levels (e.g., Kahma and Calkoen 1992). Sources of this scatter include the wind variability associated with the development of the atmospheric boundary layer as it transitions from land to water (e.g., Dobson et al. 1989, hereinafter DPT89) or the presence of strong tidal currents (Battjes et al. 1987). Observa-

DOI: $10.1175 / \mathrm{JPO} 3039.1$

(C) 2007 American Meteorological Society 
tions also support a stronger growth of waves in unstable atmospheric boundary layers, when cold winds blow over warmer waters (Kahma and Calkoen 1992; Young 1998). However, the physical mechanism that produces this stronger growth at short fetch is unknown, and this effect only accounts for a small fraction of the observed scatter. For waves approaching full development, the larger gustiness of the wind in unstable conditions should, indeed, lead to stronger growth, and this effect has been included in some wave models (Abdalla and Cavaleri 2002).

In addition to fetch, wind speed, and duration, Donelan et al. (1985, hereinafter DHH) found that the fetch geometry plays a significant role in wave development. From their analysis of Lake Ontario data, these authors found that the direction at the peak of the wave spectrum $\theta_{w}$ can differ significantly from the wind direction and proposed to rescale the fetch $X$ by the cosine of $\theta_{w}$ relative to shore normal, thus replacing $X$ with $X / \cos \theta_{w}^{*}$. The convention for the directions used here and below is that the angle $\theta$ is an arriving direction in nautical convention $\left(0^{\circ}\right.$ from north, $90^{\circ}$ from east), while $\theta^{*}$ is the same angle relative to the offshore direction. To extend the scaling of Kitaigorodskii (1962) to such cases, DHH assumed that the growth of the wave energy for waves propagating from direction $\theta^{*}$ is proportional to $U_{10} \cos ^{n}\left(\theta^{*}-\theta_{u}^{*}\right)$, with $\theta^{*}$ the wind direction (from), and $n$ a wind efficiency power (in $\mathrm{DHH}, n=1)$. The perpendicular-fetch evolution law for the inverse wave age $U / C_{p}=a\left(g X / U^{2}\right)^{b}$ with $a$ and $b$ empirical constants, may be replaced accordingly by

$$
U \cos ^{n}\left(\theta_{0}^{*}-\theta_{u}^{*}\right) / C_{p}=a\left[g X /\left(U^{2} \cos \theta_{0}^{*}\right)\right]^{b},
$$

with $a$ and $b$ unchanged and $\theta_{0}^{*}$ a representative wave direction. There is always an angle $\theta_{0}^{*}$ that satisfies (1) because the left-hand side decreases with the wind wave angle $\left(\theta_{0}^{*}-\theta_{u}^{*}\right)$, as the wind is less efficient in generating waves, while the right-hand side increases as the wave energy accumulates over a large distance. Typically $\left|\theta_{0}^{*}\right|>\left|\theta_{u}^{*}\right|$, that is, the representative wave direction is more oblique relative to the shore than the wind, and the wave spectrum is thus dominated by waves coming from this oblique "slanting fetch" direction $\theta_{0}^{*}$. DHH found that their observations supported (1) with a wind efficiency power $n=1$, in which case the representative wave direction is the peak direction $\theta_{0}^{*}=\theta_{w}^{*}$. Observations of the Canadian Atlantic Storm Program (DPT89) also support a scaling with wave direction of the form given in (1). More specifically, Perrie and Toulany (1990) found a reduced scatter for the wave energy growth when scaling the fetch and energy with $u_{*} \cos \theta_{w}^{*}$ instead of $U_{10}$.
Recent observations and numerical simulations (Pettersson 2004; Bottema and van Vledder 2005) show that nonlinear interactions, which were not accounted for in earlier directionally decoupled models (Seymour 1977; Holthuijsen 1983), play an important role in the development of waves with a slanting fetch. Yet, the balance of processes that lead to the observed spectral shapes is still poorly understood. Walsh et al. (1989) also discussed wave growth in a slanting fetch using spectra obtained from a surface contour radar. They showed that the slanting fetch effect contributed to the scatter in previous wave growth observations that include shore-oblique wind angles as large as $20^{\circ}$ (e.g., Kahma 1981) or $30^{\circ}$ (Hasselmann et al. 1973). Walsh et al. (1989) extended the analysis of DHH and found a wind efficiency power $n=1.63$ in (1) instead of $n=1$, initially proposed by DHH. This discrepancy may be the result of different fetch geometry. Also, this power $n$ cannot be simply translated in parameterizations for wave models since the different processes of wave generation, nonlinear interactions, and dissipation are parameterized separately. Further progress, including fetch geometry effects, requires a detailed hindcasting of observed wind wave growth conditions.

The objective of the present paper is to provide a better understanding of the spectral wave evolution in fetch-limited conditions, in particular, the directional distribution of wave energy. This work is based on the analysis of observations on the North CarolinaVirginia shelf collected during the Shoaling Waves Experiment (SHOWEX) in 1999 and the SandyDuck experiment in 1997 (SD97). A detailed analysis of the swell transformation in this region was presented in Ardhuin et al. (2003a,b, hereinafter referred to as AOHJ and AHJO, respectively). Here we focus on the part of the wave field that is under the direct or indirect influence of the local wind (see Watts 2003, for a preliminary analysis). To better understand the effects of slanting fetch and swell on wind wave growth, and their representation in wave forecasting models, we examine in detail two well-documented events. These two cases feature an offshore wind $20^{\circ}$ to $30^{\circ}$ relative to shore normal in the presence of swell (section 2). The implementation of two wave models, "WAVEWATCH III" (Tolman and Chalikov 1996; Tolman 2002a) and Coupled Rays with Eulerian Source Term (CREST) (Ardhuin et al. 2001; Ardhuin and Herbers 2005), with various combinations of source terms is described in section 3. Model results are compared to observations in section 4. The CREST model, using an unstructured grid, allows an optimization of the grid resolution with relatively few points, and is thus particularly well suited to the computer-intensive evaluation of "exact" nonlin- 


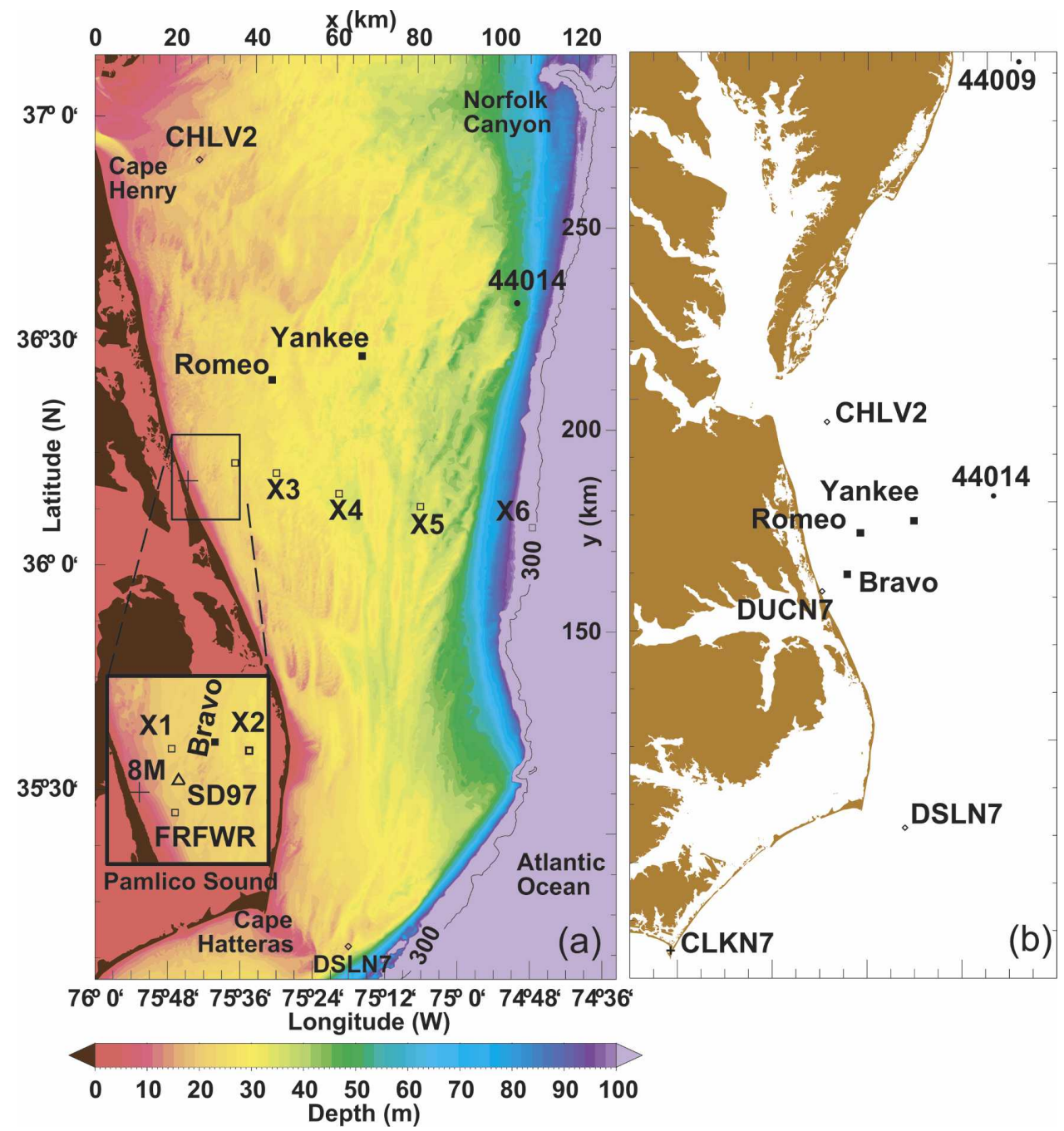

FIG. 1. (a) Bathymetry of the North Carolina shelf and locations of wave measurements during SHOWEX (1999). Array SD97 (triangle) was deployed during the earlier SandyDuck (1997) experiment. (b) Location of NDBC 3-m discus buoys (filled circles) and stations of the Coastal-Marine Automated Network (C-MAN, diamonds) providing wind measurements in and around the main area of interest. C-MAN wave measurements are made with infrared lasers and include no information on wave direction. Directional Waverider buoys (empty squares), ASIS buoys (filled squares), and the FRF 8-m pressure sensor array (large cross) are also indicated. The small cross at CLKN7 in (b) represents this land-based tower with wind measured at $9.8 \mathrm{~m}$ above ground, $11 \mathrm{~m}$ above sea level.

ear wave-wave interactions. Section 5 summarizes the results and outlines some adjustments that can be made to existing parameterizations.

\section{Datasets}

A cross-shelf transect of six Datawell Directional Waverider buoys (XI-X6) was deployed from August to December 1999 as part of the Shoaling Waves Experiment (see Fig. 1 for instrument locations). A detailed description of the data is given in AOHJ. Additional wave observations were available from the Na- tional Data Buoy Center (NDBC) 3-m discus buoy 44014, and the U.S. Army Corps of Engineers (USACE) Field Research Facility (FRF) pressure sensor array in $8-\mathrm{m}$ depth $(8 \mathrm{M})$ and the Waverider buoy FRFWR. Wind measurements in and around the study area were obtained from the NDBC archives (Fig. 1b). Last, three Air-Sea Interaction Spar (ASIS) buoys (Graber et al. 2000) were deployed on the shelf to measure waves and turbulence (Fig. 1). The instrumentation on each buoy included an array of eight wave staffs to measure wave directional properties (Pettersson et al. 2003), a sonic anemometer to measure wind and 
wind stress (Drennan et al. 2003), and a full-motion package, which was used to correct the wave staffs and anemometer for motion of the buoy (Anctil et al. 1994). Here we use data from the inshore ASIS buoy Bravo, the position of which is roughly aligned with the transect of the Waverider buoys.

Earlier, in the 1997 SandyDuck experiment, frequency-directional wave spectra on the inner shelf were measured with a 500-m aperture triangular array of nine seafloor pressure sensors located $5 \mathrm{~km}$ from the shoreline, in 20-m depth (SD97 in Fig. 1). The spacing of the pressure sensors was varied from 20 to $500 \mathrm{~m}$ in order to resolve waves at swell frequencies (0.05-0.16 $\mathrm{Hz}$ ) as well as lower-frequency infragravity waves. The higher frequency portion of the spectrum $(0.16-0.5 \mathrm{~Hz})$ that is attenuated at the seafloor was measured with a Datawell Directional Waverider buoy also deployed within the perimeter of the array.

Frequency-directional spectra were estimated at all wave measurement sites, using the maximum likelihood method for the $8 \mathrm{M}$ and Bravo array (Long and Atmadja 1994), a variational method (Herbers and Guza 1990) for the SD97 array, and the maximum entropy method (Lygre and Krogstad 1986) for the Directional Waverider buoys. Mean wave direction and directional spread, as function of frequency, were also estimated using a standard technique based on the first Fourier moments of the directional distribution of energy (e.g., Kuik et al. 1988). The estimation of these parameters from Waverider buoys is known to be robust and accurate, at least at the peak frequency (O'Reilly et al. 1996).

\section{a. Observations of wave generation for moderately slanting fetch with opposing swell}

From now on the angle relative to shore normal $\theta^{*}=$ $\theta-250^{\circ}$ is defined based on the coastline orientation at Duck where the experiments were centered. We have selected a wind event on 3 November 1999 that closely resembles idealized fetch-limited generation conditions. Forcing conditions are characterized by a moderate $\left(U_{10}=9.5 \mathrm{~m} \mathrm{~s}^{-1}\right)$ fairly steady and uniform wind blowing offshore with $\theta^{*}=10-30^{\circ}$ (Fig. 2). Measurements at the Duck pier, ASIS buoys, and buoy 44014 give air temperatures $6^{\circ}-10^{\circ} \mathrm{C}$ colder than the ocean, making the atmospheric boundary layer unstable. Moderate onshore swells nearly oppose the local wind sea. Wave observations were averaged over $5 \mathrm{~h}$ from 1200 to $1700 \mathrm{EST}$ ) in order to reduce the uncertainty of the estimated spectral parameters. In spite of variations on the order of $15 \%$ from the mean wind speed, the averaged wave spectra are expected to be representative of steady conditions with the same mean wind, due to the
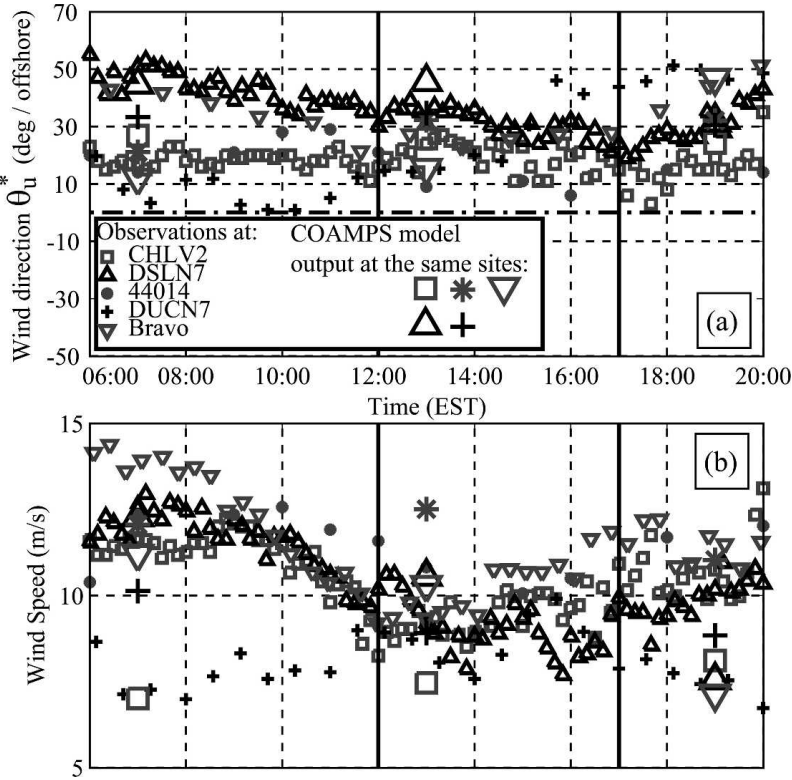

FIG. 2. Measured (small symbols) and predicted (large symbols) (a) 10-m neutral wind speed and (b) wind direction on 3 Nov 1999 at five stations near the instrumented transect.

relatively fast variations in wind speed compared to the time scale of wave development.

Above $0.15 \mathrm{~Hz}$, the observed spectra (Fig. 3a) show the well-known behavior of fetch-limited growth with an overshoot of the spectral peak over the saturation level (Barnett and Sutherland 1968). Below $0.15 \mathrm{~Hz}$ the observed spectra are dominated by the southeasterly swell with a peak period $T_{p} \approx 10 \mathrm{~s}$ and significant wave height $H_{s} \approx 1 \mathrm{~m}$, decreasing from offshore to the coast. The mean direction and directional spread as a function of frequency (Figs. 3b,c) clearly reveal the presence of these two well-defined directionally narrow and opposing wave systems at buoys X4-X6. Inshore of X3, the energy spectrum contains a plateau at about $0.2 \mathrm{~Hz}$, with mean directions $\theta_{m}^{*}$ between $80^{\circ}$ (northwest) and $110^{\circ}$ (northeast, Fig. 3b). The alongshore propagation direction of these intermediate frequency waves indicates that they are locally generated on the shelf, and thus part of the same wind sea, affected by refraction and/or the slanting-fetch condition.

Few detailed field observations of wave growth in the presence of opposing swell have been reported. DPT89 concluded from observations off Nova Scotia that swell has no significant impact on wind-sea growth. To our knowledge, no study based on field data has reported any significant effect of the swell on wind-sea growth. To verify this finding, we isolate the wind sea and compare our observations with the historical datasets of fetch-limited wave growth discussed by Hasselmann et al. (1973) and Kahma (1981), and synthesized by 


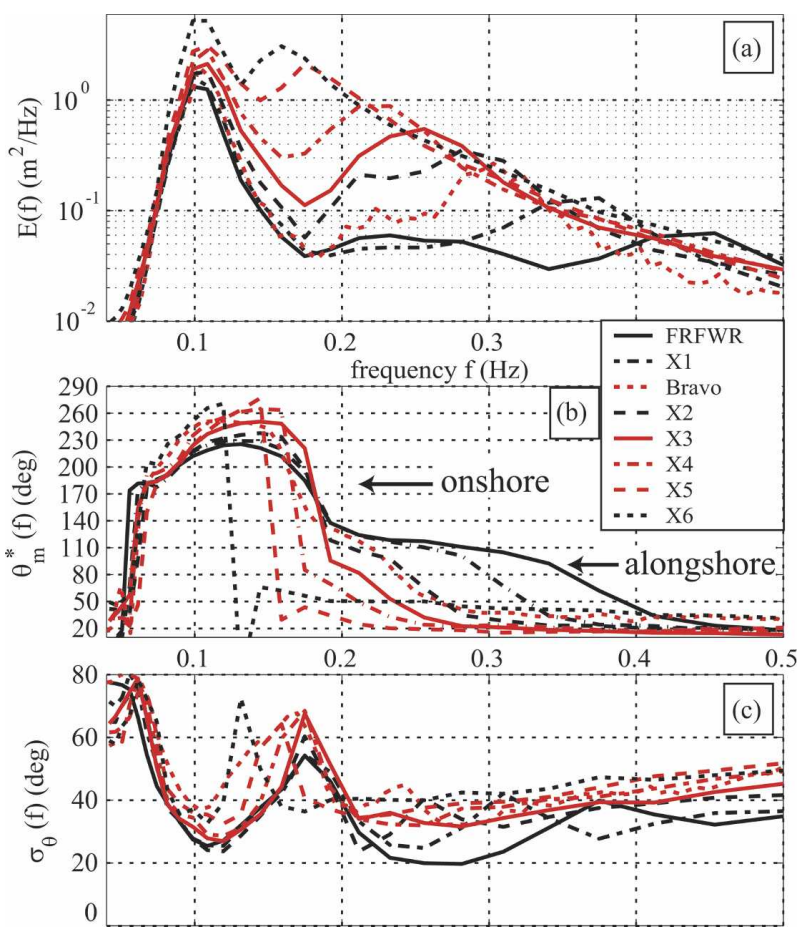

FIG. 3. Observed (a) frequency spectra, and both as a function of frequency (b) mean directions and (c) directional spreads on 3 Nov 1999 (averages over the 1200-1700 EST time interval). Note that the Bravo data were not interpolated on the same frequency grid as the other sensors.

Kahma and Calkoen (1992). The present coastal wind measurements comply with the criteria used in these studies, with a wind direction within $30^{\circ}$ of shore normal (Hasselmann et al. 1973), and a reasonably stable and uniform wind speed and direction.

To make a meaningful comparison, some effect of the wind and wave angle ought to be included in the definition of the nondimensional fetch. Because at short fetch the wave direction varies rapidly with frequency and because the wave direction is not reported by Kahma (1981), we define the dimensionless fetch $X^{*}$, like Kahma, as the fetch in the wind direction: $X^{*}=X g \cos \theta_{u}^{*} / U_{10}^{2}$, with $X$ being the distance perpendicular to the coast, and $\theta_{u}^{*}$ being the wind direction used here instead of the more oblique peak wave direction used by DHH. Wind measurements were averaged over all four stations and the 5-h time period, giving $U_{10}=9.43 \mathrm{~m} \mathrm{~s}^{-1}$ and $\theta_{u}^{*}=20^{\circ}$ values used to estimate $X^{*}$, and the dimensionless energy $E^{*}=E g^{2} /$ $U_{10}^{4}$ and peak frequency $f_{p}^{*}=f_{p} U_{10} / g$, with $g=9.81$ $\mathrm{m} \mathrm{s}^{-1}$. It should be noted, however, that the wind speed increased from the shore to the open ocean (Fig. 2b), consistent with the development of the atmospheric boundary layer (e.g., DPT89). Last, following DPT89, we remove the swell component in our observations.
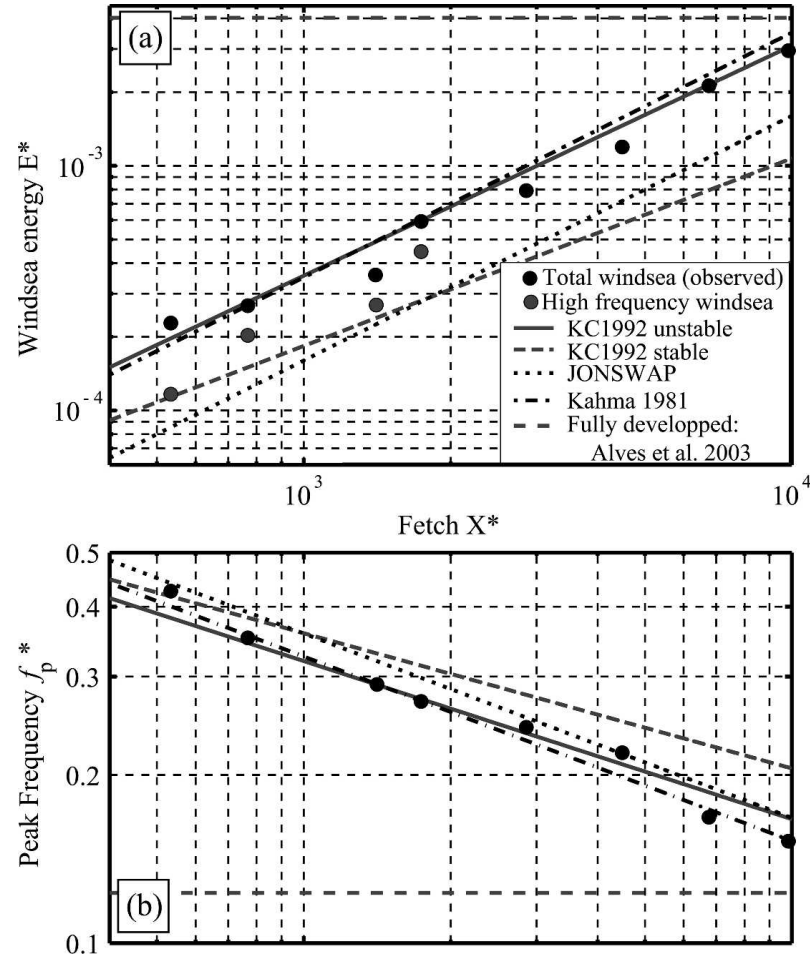

FIG. 4. Observed cross-shelf evolution of dimensionless windsea energy and peak frequency on 3 Nov 1999 (determined from spectra shown in Fig. 3) are compared with previously published growth curves. The total wind-sea energy (black dots) is at frequencies above the first maximum of the directional spread (see Fig. 3c), while the "direct wind sea" energy (red dots) is at frequencies above the second maximum of the directional spread (see Fig. 3c).

The wind-sea energy is defined, somewhat arbitrarily, as the energy at frequencies above the first local minimum in the wave frequency spectrum $E(f)$ (Fig. 3a). These waves come from directions ranging from east to north (Fig. 3b), which are easily distinguished from the southeasterly swell.

The present case covers a large range of wave conditions, with $470<X^{*}<8700$, that complements the more developed waves $1100<X^{*}<24000$ observed by Walsh et al. (1989). Evolution of $E^{*}$ and $f_{p}^{*}$ with $X^{*}$ (Fig. 4) are in close agreement with the growth curves of Kahma (1981) obtained for a similarly unstable atmospheric boundary layer. Kahma's (1981) results are based on data with similar slanting fetches on the order of $20^{\circ}$, and he carefully removed from his analysis all cases where a swell was present. We thus conclude that the moderate swell in the present data has no significant effect on the main parameters defining the wind sea, consistent with previous field observations (DPT89; Hanson and Phillips 1999). This result may seem at variance with the laboratory experiments of 
TABLE 1. Main parameters in cases of observed interactions of short and long waves. The mean square slope of the long waves is defined as $\mathrm{mss}_{\text {long }}=\int_{0}^{f_{c}} k^{2} E(\mathbf{k}) d \mathbf{k}$ with a cutoff frequency $f_{c}$ between the long and short waves, $C_{s}$ is the phase velocity of the short waves, $\theta_{\mathrm{lw}}$ is the direction of the long waves.

\begin{tabular}{lcc}
\hline \hline & Donelan (1987) & This study \\
\hline $\mathrm{mss}_{\text {long }}$ & $2.5-11 \times 10^{-3}$ & $1.8-4 \times 10^{-4}$ \\
$\left|\theta_{u}-\theta_{\mathrm{lw}}\right|$ & $0^{\circ}$ & $110-150^{\circ}$ \\
$C_{s} / u_{*}$ & $1-4$ & $8-25$ \\
$\Delta T$ & $0^{\circ}$ & -10 to $-6^{\circ} \mathrm{C}$ \\
\hline
\end{tabular}

Phillips and Banner (1974) and Donelan (1987), who observed a large impact of mechanically generated waves on wind wave growth. Compared to laboratory conditions, the effect of swell on wind-sea growth is likely reduced in field conditions because the mean Eulerian shear observed in field conditions is weaker (Santala and Terray 1992), and the steepness of natural swells is lower, resulting in weaker effects on wave breaking (Phillips and Banner 1974; Donelan 2001). The sheltering of short waves by long waves, which likely causes some of the observed interactions between short and longer waves in the laboratory, is also expected to occur only when the long waves are still relatively young, propagating in the wind direction (Chen and Belcher 2000). The differences between wind and wave parameters for the present case and the laboratory measurements of Donelan (1987) are summarized in Table 1.

Wave energies observed here are still well above the Joint North Sea Wave Project (JONSWAP) growth curve at all fetches (Fig. 4) and close to the growth curve for unstable conditions given by Kahma and Calkoen (1992). Nevertheless, at FRFWR the spectrum contains a distinct slanting-fetch component below the wind-sea peak frequency. Removing this slanting-fetch wind sea yields a direct wind-sea energy closer to the JONSWAP growth curve. The peak of the directional spread may be used to estimate a cutoff frequency between the two wind-sea systems at other nearshore stations, giving direct wind-sea energies shown in Fig. 4. These estimates show that both slanting-fetch effects and the unstable atmosphere may contribute to the enhanced growth.

\section{b. Slanting- and "remote" fetch effects}

An unusual wind-sea event was recorded during the SandyDuck nearshore experiment. On 16-18 August 1997 the wind was blowing from the southwest with moderate wind speeds, $U_{10}=8 \mathrm{~m} \mathrm{~s}^{-1}$ at the pier of the Duck U.S. Army Corps of Engineers Field Research Facility (station DUCN7). The angle of the wind rela-
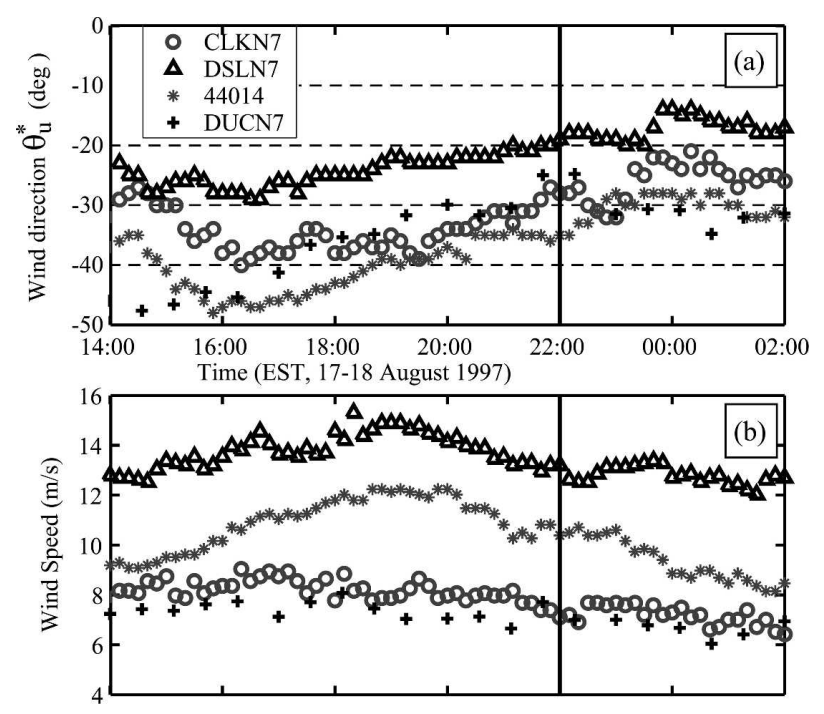

FIG. 5. Measured (a) 10-m neutral wind speed and (b) wind direction on 17 Aug 1997, at four stations on the shelf.

tive to shore normal was $\theta_{u}^{*} \simeq 30^{\circ}$ at DUCN7, only slightly larger than in the previous case. However, the main generation area (where the winds are strongest, $U_{10}=13 \mathrm{~m} \mathrm{~s}^{-1}, \theta_{u}^{*} \simeq 20^{\circ}$ ) is remotely located, south of the wave measurement sites (Fig. 5). Unusual longcrested but short wavelength waves, arriving at very large oblique angles, were observed at Duck (pictures are available from the USACE FRF Web site at ftp:// dksrv.usace.army.mil/pub/argus02/1997/c2/229_aug.17/ 871860120.sun.aug.17_23.22.00.gmt.1997.c2.snap.jpg). We focus on waves recorded from 2200 to 0200 EST 17-18 August, after a period of steady and uniform winds (Fig. 5).

The measured $H_{s}$ was $0.29 \mathrm{~m}$ at $8 \mathrm{M}$ with most of the energy in the $0.12-0.35-\mathrm{Hz}$ band (Fig. 6). The mean wave direction of $105^{\circ}$ at the peak frequency in 8-m depth (Fig. 6b) corresponds to $35^{\circ}$ from shore normal. With such a large oblique incidence angle, a strong refraction of waves toward the beach was observed. Energy at frequencies below $0.12 \mathrm{~Hz}\left(H_{s}=0.15 \mathrm{~m}\right)$ with directions between $50^{\circ}$ and $100^{\circ}$ can be ascribed to swells arriving from the North Atlantic, but the higher frequency energy corresponds to waves generated on the shelf. At the SD97 array farther offshore in 20-m depth, the seas were more energetic $\left(H_{s}=0.44 \mathrm{~m}\right)$ and the mean direction $\left(\theta^{*}=-100^{\circ}\right)$ is almost parallel to the shoreline $\left(\theta^{*}=-90^{\circ}\right)$. The decrease in height and shift in direction between SD97 and 8M can be explained by refraction. However, the mean wave direction at SD 97 still differs by $75^{\circ}$ from the wind direction, which is larger than the maximum angles of about $50^{\circ}$ observed by Donelan et al. (1985) in slanting-fetch conditions. Model predictions presented in section 4 show 

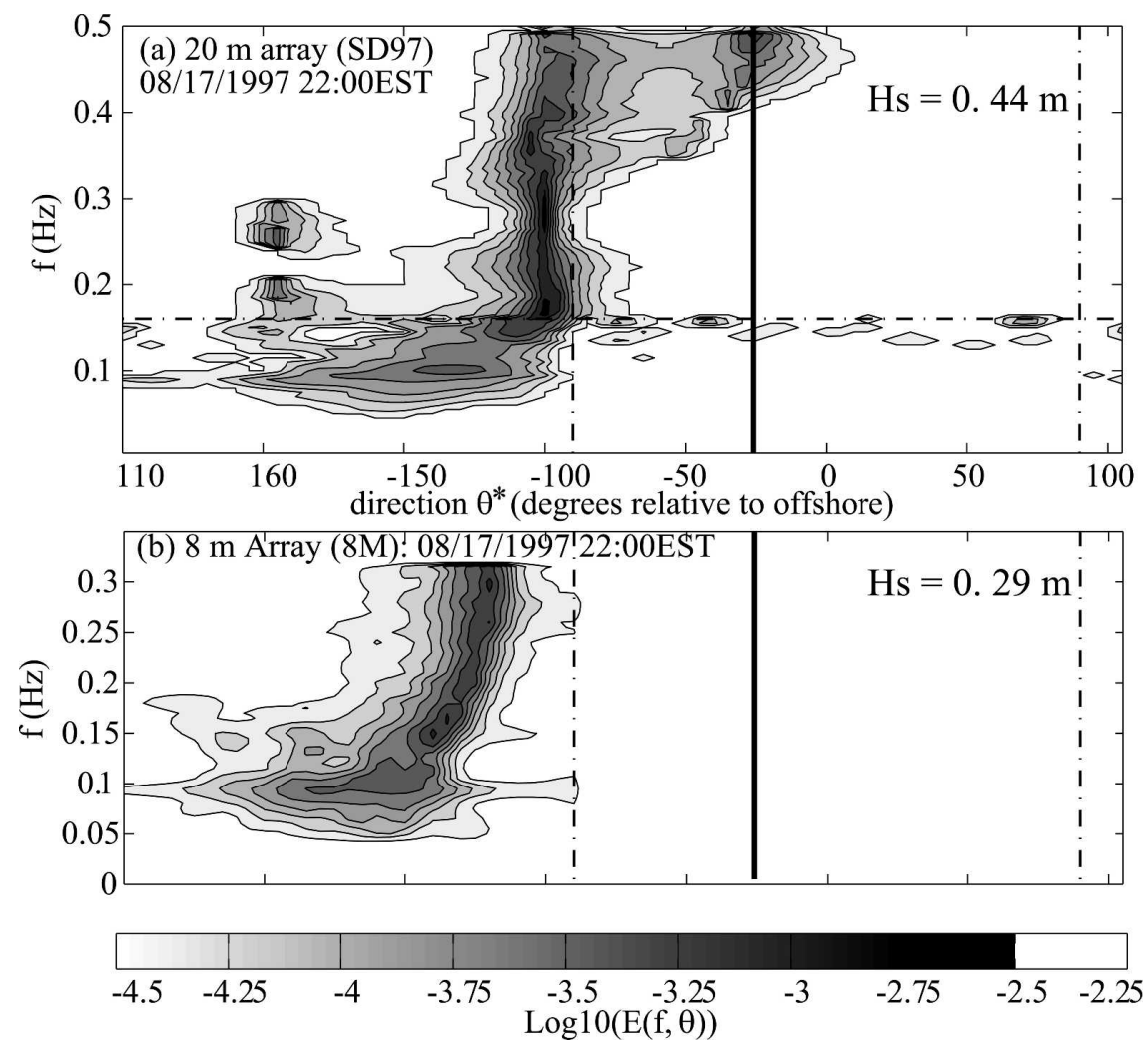

FIG. 6. Observed wave spectra on 17-18 Aug 1997 (averaged over the time interval 22000200 EST) for the (a) SD97 and (b) 8M arrays. The solid thick vertical line indicates the wind direction, and the two dash-dotted lines indicate alongshore directions (normal incidence is $70^{\circ}$ ). In (a) the horizontal line separates spectrum estimates based on pressure array and Waverider buoy data.

that refraction effects on these waves are negligible at the SD97 site.

In these two events a significant amount of wave energy was generated at large angles with respect to the wind direction, even for small angles of the wind relative to the shoreline. This situation results in complex spectra at short fetch $\left(X^{*} \leq 2000\right)$ with a strong variation of the mean wave direction with frequency. Such observed wave conditions are the likely result of a complex balance of wave generation, dissipation, and nonlinear interaction, which can be investigated with numerical models. Comparison with previous observations without swell also suggests that a moderate swell $\left(H_{s}=1 \mathrm{~m}\right)$ has no effect on the wind sea in deep water, but the complex mixed swell-wind wave spectra provide a demanding test for the robustness of wave prediction models.

\section{Numerical wave models}

\section{a. Parameterizations of source terms}

Neglecting the effect of mean currents, the wave evolution problem can be formulated with a balance equa- tion for the surface elevation variance spectrum $E(\mathbf{k})$ (Gelci et al. 1957; see also Komen et al. 1994). This representation of wave evolution effectively decouples the well-understood linear propagation physics from the less-understood forcing, scattering, and dissipation processes that are parameterized in the form of spectral "source terms" $S_{i}(\mathbf{k})$,

$$
\frac{d E(\mathbf{k})}{d t}=S_{\mathrm{tot}}=\sum_{i} S_{i}(\mathbf{k})
$$

The net rate of growth (or decay) of a spectral component, following its ray trajectory with its group velocity, is the sum of all source terms, each representing a clearly defined physical process.

The effect of quartet wave-wave interactions is represented by the scattering term $S_{\mathrm{nl}}$ (Hasselmann 1962). This term is usually parameterized using the discrete interaction approximation (DIA) $S_{\mathrm{nl}}^{\text {DIA }}$ (Hasselmann et al. 1985). This shortcut is taken because the "exact" calculation is generally too time consuming. Calculations are done here with $S_{\mathrm{nl}}^{\mathrm{DIA}}$ and a full calculation of the interaction $S_{\mathrm{nl}}^{\mathrm{WRT}}$ (van Vledder 2006), based on the method of Webb, Resio, and Tracy [WRT; Webb 
(1978; Tracy and Resio (1982)]. The deep water estimate of $S_{\mathrm{nl}}^{\mathrm{WRT}}$ is used for simplicity and corrected for finite depth following Herterich and Hasselmann (1980; see also van Vledder 2006). That finite depth correction has no effect in the present calculations because the water depth increases as the wind sea develops, effectively maintaining deep water conditions along the entire fetch.

The other source terms include the transfer of energy from wind to waves $S_{\text {in }}$, and the loss of wave energy $S_{\mathrm{ds}}$ resulting from the formation of whitecaps and the associated turbulence in the upper ocean. In shallow water, waves are also dissipated by bottom friction, while scattering due to small-scale water depth variations affects wave directional properties (Ardhuin and Herbers 2002; AOHJ). These two terms are included in calculations with CREST but are negligible here, mainly due to the low amplitude and not too low frequency of the incoming swells (see AHJO). Model results run with and without these terms are nearly identical. The present analysis is focused on water depths $\geqslant 8 \mathrm{~m}$, with offshore winds, and swell heights lower than $2 \mathrm{~m}$. In these conditions, effects of depth-induced breaking and triad wave-wave interactions are small (see, e.g., Herbers et al. 2003) and will be neglected.

For moderate winds and waves propagating in the wind direction with phase speeds larger than $U_{10} / 3$, the magnitude of $S_{\text {in }}$ is well represented by the Snyder et al.'s (1981) source function $S_{\text {in }}^{\text {SDEL }}$, based on direct measurements of the correlation of air pressure and surface slope. Janssen's (1991) source function $S_{\text {in }}^{\mathrm{J}}$ gives a growth factor that roughly agrees with these measurements for waves propagating in the wind direction, and may also be appropriate for higher frequency waves (Janssen 2004). This implies that the source function $S_{\text {in }}^{\text {TC }}$ fitted by Tolman and Chalikov (1996) to the numerical predictions of air flowing over waves (e.g., Chalikov and Belevich 1993) probably underestimates wind wave growth for $C / U_{10}>1 / 3$. The distribution of the growth rate $S_{\text {in }} / E$ as a function of wave angle $\theta$ is still unknown (e.g., Banner and Young 1994), and some wave models have adopted rather narrow distributions proportional $^{1}$ to $\cos ^{n}\left(\theta-\theta_{u}\right)$, with $n=2$ for $S_{\text {in }}^{J}$, and not too far from $\cos ^{2}\left(\theta-\theta_{u}\right)$ for the high frequency range in $S_{\text {in }}^{\mathrm{TC}}$ relative to the much broader $n=1$ for $S_{\text {in }}^{\mathrm{SDEL}}$.

The loss of wave energy owing to whitecapping and its spectral distribution $S_{\mathrm{ds}}$ is even more uncertain. Most of the parameterizations used here follow Komen et al. (1984, hereinafter KHH; see appendix A). This

\footnotetext{
${ }^{1}$ This notation is used for simplicity although this expression only applies for $\left|\theta-\theta_{u}\right|<\pi / 2$ and is set to zero otherwise.
}

approach is based on Hasselmann's (1974) conceptual model of whitecaps acting as pressure pulses that work against the underlying waves. The weak point in this family of parameterization is the definition of a spectrum-averaged steepness, which leads to anomalous swell effects on wind wave growth. The present observations, and those by DPT89, suggest that moderate swells do not impact wind wave growth, and thus a proper parameterization of wave dissipation should also fully dissociate the dissipation of swells, believed to be caused by the wind and upper ocean turbulence (e.g., Kudryavtsev and Makin 2004; Ardhuin and Jenkins 2005, 2006), from the direct loss of energy of the wind sea owing to whitecapping. Such an approach was used by Tolman and Chalikov (1996), with a source term $S_{\mathrm{ds}}^{\mathrm{TC}}$.

\section{b. Model settings: WAVEWATCH III}

Version 2.22 of WAVEWATCH III (hereinafter WW3) is the basis of the computer code used here (Tolman 2002a). The model is run with the default thirdorder QUICKEST advection scheme and "garden sprinkler effect" reduction scheme. The model grid is regular in latitude and longitude with $1 / 60^{\circ}$ resolution $(1.5-1.8 \mathrm{~km})$. Water depths are derived from a combination of National Oceanographic Data Center (NODC) archives and dedicated surveys (Fig. 1: see AOHJ for details).

The offshore model boundary was roughly fitted to a position slightly offshore of the shelf break, reducing the number of computation points to 9603 (Fig. 7a). The spectral grid uses 36 directions regularly spaced over a full circle (i.e., a directional resolution of $10^{\circ}$ ) and 30 frequencies from 0.0418 to $0.73 \mathrm{~Hz}$, exponentially spaced with a factor- of 1.1 increment. The model was integrated with a 60-s time step for geographical and spectral advection. The fractional time step implementation in WW3 allows a larger source term integration step, here fixed at $600 \mathrm{~s}$ with an adaptive refinement to $150 \mathrm{~s}$ when necessary. The relatively coarse $10^{\circ}$ resolution was chosen to allow a reasonable computation time with $S_{\mathrm{nl}}^{\mathrm{WRT}}$ in CREST. Runs with $5^{\circ}$ resolution yielded only slight reductions (about $3^{\circ}$ ) in the directional spread.

\section{c. Model settings: CREST}

The spectral grids of CREST and WW3 are identical. The source term integration scheme in CREST is as close as possible to the one in WW3, with details given in appendix B. The main difference between the two models is the semi-Lagrangian advection scheme used in CREST. The CREST scheme is based on backward ray tracing from the nodes of an unstructured grid and 


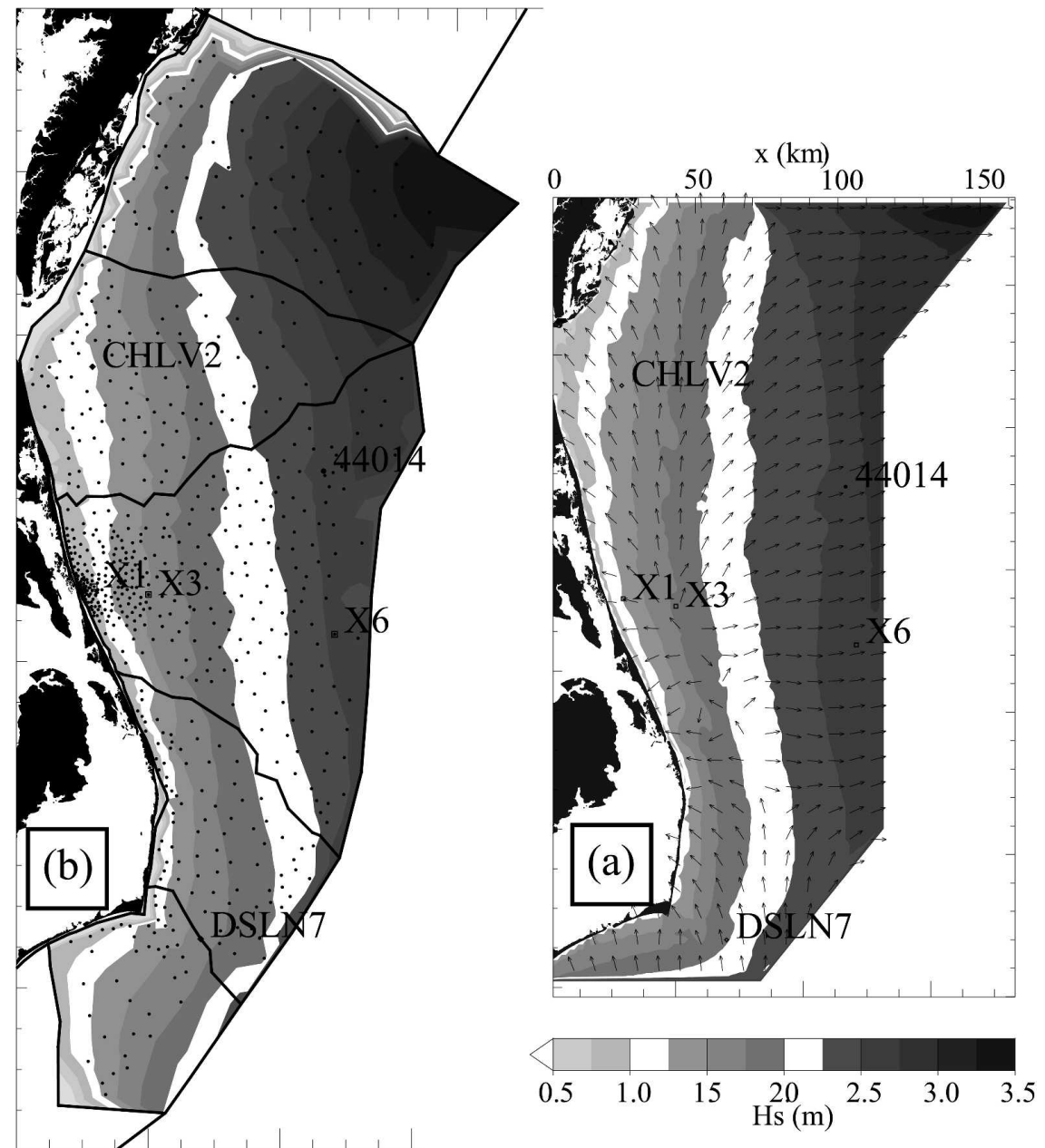

FIG. 7. (a) WW3 and (b) CREST model domains showing the significant wave height and mean wave direction calculated with the JHHK parameterization at 1500 EST 3 Nov 1999, including incoming swells from the Atlantic. One arrow out of five, in each direction, is shown in (a). The dots in (b) are all the CREST grid points, and the thick lines mark model subdomain boundaries (see $\mathrm{AOHJ}$ ).

an interpolation of source terms from the grid to the rays (Ardhuin et al. 2001; Ardhuin and Herbers 2005). The present grid is composed of 854 points, with a resolution of $1 \mathrm{~km}$ close to the coast at Duck increasing to $10-15 \mathrm{~km}$ offshore (Fig. 7b). This low number of grid points allows the calculation of $S_{\mathrm{nl}}^{\mathrm{WRT}}$ in nonstationary conditions. Advection is performed along the precomputed rays with a fixed time step $\Delta t=600 \mathrm{~s}$. To enhance computational efficiency, the rays are terminated at an integer number $m$ of advection time steps. At the ray end points, the energy spectral density is interpolated from surrounding points (Ardhuin and Herbers 2005). Here we use $m=4$ steps at the lowest frequencies (the range in which the swell is observed) and $m=1$ at the highest frequencies (tests with $m=2$ and $m=3$ gave no significant differences).

\section{d. Summary of model runs}

As shown in appendix B, the two models generally give very similar results, and will thus be considered equivalent. From now on, all model runs that use $S_{\mathrm{nl}}^{\mathrm{DIA}}$ will be obtained with WW3, unless otherwise stated, while all model runs with $S_{\mathrm{nl}}^{\mathrm{WRT}}$ are performed with CREST.

Results are shown for

- $S_{\mathrm{tot}}^{\mathrm{TC}}=0.36 S_{\mathrm{nl}}^{\mathrm{DIA}}+S_{\mathrm{in}}^{\mathrm{TC}}+S_{\mathrm{ds}}^{\mathrm{TC}}$ : This combination represents the default parameterization for WW3 that is used for operational forecasting at the National Oceanographic and Atmospheric Administration National Centers for Environmental Prediction.

- $S_{\mathrm{tot}}^{\mathrm{JHHK}}=S_{\mathrm{nl}}^{\mathrm{DIA}}+S_{\mathrm{in}}^{\mathrm{J}}+S_{\mathrm{ds}}^{\mathrm{JHHK}}$ : This combination represents the default parameterization WAM cycle 4 
(see appendix A), which is close to what was used for operational forecasting at the European Centre for Medium-Range Weather Forecasts (ECMWF) until March 2005. The code was adapted for WW3 from a 2001 version of the WAM code.

- $S_{\mathrm{tot}}^{\mathrm{BAJ}}=S_{\mathrm{nl}}^{\mathrm{DIA}}+S_{\mathrm{in}}^{\mathrm{J}}+S_{\mathrm{ds}}^{\mathrm{BAJ}}$ : This is the new parameterization used since April 2005 in the operational WAM model at ECMWF (Bidlot et al. 2007; see also appendix A).

- $S_{\mathrm{tot}}^{\mathrm{JHHK}+\mathrm{WRT}}=S_{\mathrm{nl}}^{\mathrm{WRT}}+S_{\mathrm{in}}^{\mathrm{J}}+0.7 S_{\mathrm{ds}}^{\mathrm{JHHK}}$ : In this set of source terms the dissipation was reduced. A full retuning of the dissipation functional form would be necessary to obtain reasonable spectral shapes (Banner and Young 1994). To facilitate comparisons with other runs, a simple $30 \%$ reduction of the dissipation is used. This mitigates some of the biases in the $\mathrm{KHH}$ dissipation discussed by Banner and Young (1994), who suggested a larger reduction $(50 \%)$. Such a larger reduction, however, leads to a faster and unrealistic wave growth with this choice of $S_{\text {in }}$.

- $S_{\mathrm{tot}}^{\mathrm{WAMDI}+\mathrm{WRT}}=S_{\mathrm{nl}}^{\mathrm{WRT}}+S_{\mathrm{in}}^{\mathrm{SDEL}}+0.7 S_{\mathrm{ds}}^{\mathrm{JHHK}}$ : This is similar to the previous set of source terms and is used to investigate the impact of the directional distribution of $S_{\text {in }}$.

For the sake of clarity we have omitted in this list the bottom friction and scattering terms, which appeared negligible in the present cases.

\section{Model hindcasts}

\section{a. Preliminary test of air-sea stability and gustiness effects}

Motivated by the analyses of Kahma and Calkoen (1992) and Walsh et al. (1989), a first series of tests was performed to investigate the potential effect of wind direction errors and evaluate air-sea stability parameterizations. The WW3 model was thus run with uniform and steady wind fields with $U_{10}=9.43 \mathrm{~m} \mathrm{~s}^{-1}$ and three wind directions $\left(\theta_{u}^{*}=0^{\circ}\right.$, which is offshore, $20^{\circ}$, and $30^{\circ}$ ). Calculations use air-sea temperature differences $\Delta T=2^{\circ} \mathrm{C}$ (stable) and $\Delta T=-10^{\circ} \mathrm{C}$ (unstable). The stability correction to $S_{\text {in }}^{\mathrm{J}}$ is based on the gustiness parameterization of Abdalla and Cavaleri (2002), implemented with the method of Abdalla and Bidlot (2002). The stability correction for $S_{\text {in }}^{\mathrm{TC}}$ is Tolman's (2002b) effective wind speed $U_{e}$ (increased when unstable) so that the wave growth reproduces Kahma and Calkoen's (1992) stable and unstable growth curves. This parameterization with $\Delta T=-10^{\circ} \mathrm{C}$ and $U_{10}=$ $9.43 \mathrm{~m} \mathrm{~s}^{-1}$ yields $U_{e}=11.7 \mathrm{~m} \mathrm{~s}^{-1}$.

Model runs (Fig. 8) suggest that a wind direction shift from shore normal $\left(0^{\circ}\right)$ to $30^{\circ}$ can give differences in $E^{*}$

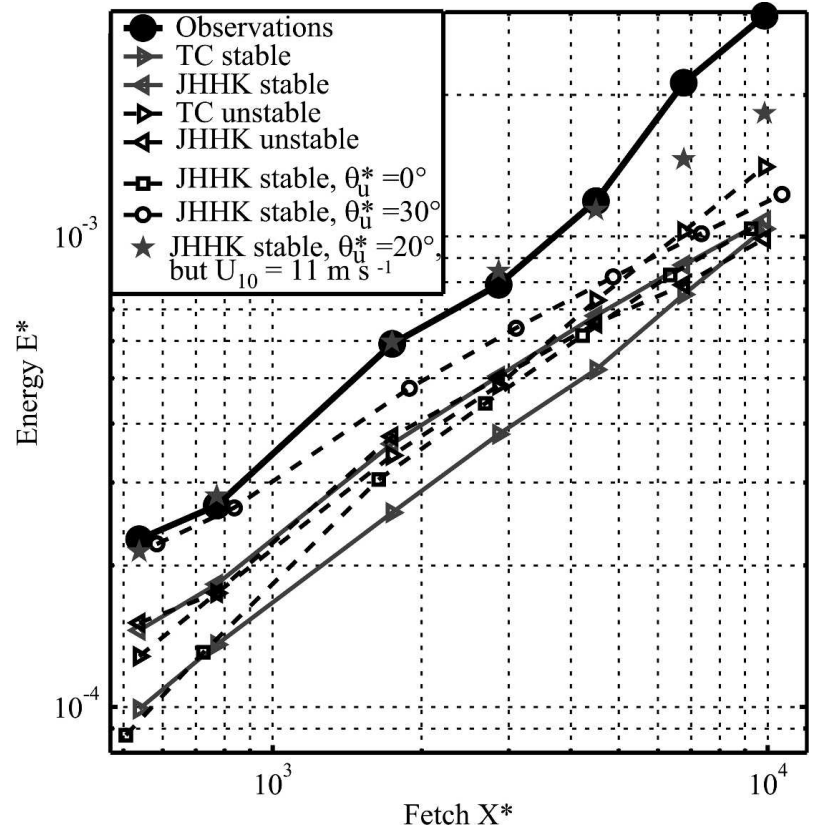

FIG. 8. Cross-shelf evolution of dimensionless wind-sea energy given by the model WAVEWATCH III for several parameterizations. Uniform winds are used (speed $U_{10}=9.43 \mathrm{~m} \mathrm{~s}^{-1}$ and direction $\theta_{u}^{*}=20^{\circ}$, unless stated otherwise). Unstable parameterizations by Tolman (2002b) for TC and Abdalla and Cavaleri (2002) for WAM cycle 4 use an air-sea temperature difference of $-10^{\circ}$.

comparable to those between Kahma (1981) and the JONSWAP data for $X^{*}<0.001$. Such a large effect of the wind direction was indeed observed by Perrie and Toulany (1990). Further, the effect of increasing the model wind speed from 9.43 to $11 \mathrm{~m} \mathrm{~s}^{-1}$ is comparable at short fetch to a wind direction change from $20^{\circ}$ to $30^{\circ}$ (in that case also the computed energy is normalized by $U_{10}=9.43 \mathrm{~m} \mathrm{~s}^{-1}$ ). Thus, if the directional distribution of energy from the wave models is to be trusted, the wind angle is a quite sensitive parameter, with a typical error of $10^{\circ}$ being as important as a $10 \%$ change in the wind speed.

Such a change in wind speed is on the order of the effective wind increase parameterized by Tolman (2002b) for unstable conditions, resulting in about $50 \%$ larger wave energies (Fig. 8). In contrast, for a wind generation term that is linearly related to the wind speed, the gustiness produced in unstable conditions only affects waves that are close to full development (Abdalla and Cavaleri 2002), which is not the case here (Fig. 8). The variability in the wind direction, not necessarily related to $\Delta T$, may be as large as $10^{\circ}$ in some situations (Abdalla and Cavaleri 2002), and could have some impact in slanting-fetch conditions. In view of the poor knowledge of these effects, from now on we shall 
use "standard parameterizations" that do not account for air-sea stability or gustiness effects.

\section{b. Realistic hindcasts: General settings}

Model hindcasts and observations are now compared, accounting for the effects of irregularities and unsteadiness of wind and waves. The models were run in nonstationary mode, starting from rest at 2300 EST 2 November. Models were forced by 6-hourly winds that combine a succession of one analysis and one 6-h forecast from the twice-daily cycles (0000 and 1200 UTC) of the Coupled Ocean/Atmosphere Mesoscale Prediction System (COAMPS) atmospheric model run at Fleet Numerical Meteorological and Oceanographic Center (Hodur 1997). Model results and observations were averaged over the 1200-1700 EST time frame, giving 1800 degrees of freedom per $0.05-\mathrm{Hz}$ band, with an expected accuracy of $5 \%$ in spectral estimates averaged over 0.05 $\mathrm{Hz}$ (the model spectral resolution at high frequency) at the $95 \%$ confidence level.

The wave field produced by the models generally corresponds to observations, including the presence of waves from the north due to the slanting fetch. On the midshelf, both wind waves and swell are present with almost equal energies. Fetch from the northwest is larger than fetch from the southwest around the instrumented array; thus the dominant wind-sea direction is from the northwest, veering west on the outer shelf. The wave field is best understood by looking at the evolution of the full frequency-direction spectra (Fig. 9). The change in wind-sea direction with frequency is most pronounced close to the coast. Using $S_{\mathrm{nl}}^{\mathrm{WRT}}$, the modeled spectra evolve toward a bimodal distribution offshore, for $f>2 f_{p}$, owing to the effect of the nonlinear interactions, consistent with the observations of Young et al. (1995) and modeling by Hasselmann et al. (1985). However, the shape of the directional spectrum varies widely with parameterization choices.

Because Waverider buoys do not measure the details of the directional spectrum, only the energy, mean direction, and directional spread are compared with observations. Runs obtained with a flat and deep bottom yield wind-sea predictions that cannot be distinguished from those in runs with the actual bathymetry, indicating that depth-induced refraction is insignificant at the measurement locations (not shown). We first evaluate model predictions without swell.

\section{c. Hindcasts without swell: Slanting-fetch effects in wave models}

When forcing with the local wind only, excluding swell arriving through the offshore model boundary, reasonably accurate frequency wind wave spectra are
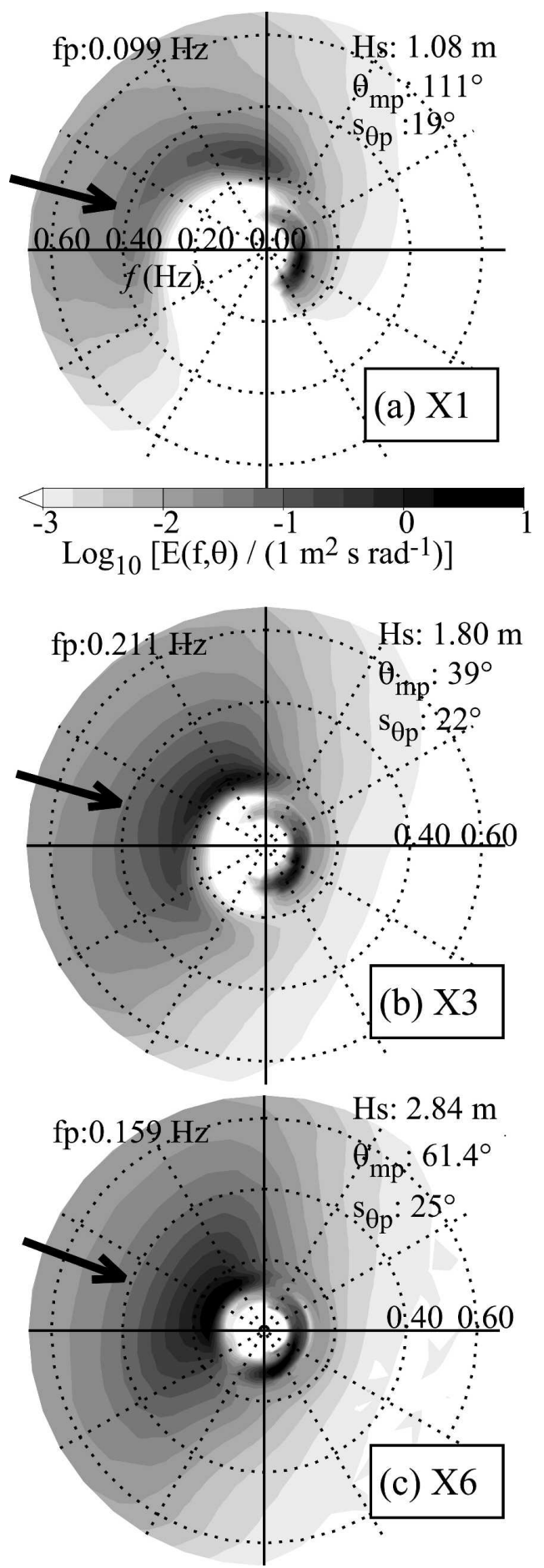

FIG. 9. Example of modeled wave spectra at (a) X1, (b) X3, and (c) X6 obtained with the parameterization WAMDI + WRT. Thick arrow indicates the model wind directions. The nonstationary model runs were averaged over $5 \mathrm{~h}$ from 1200 to 1700 EST. 

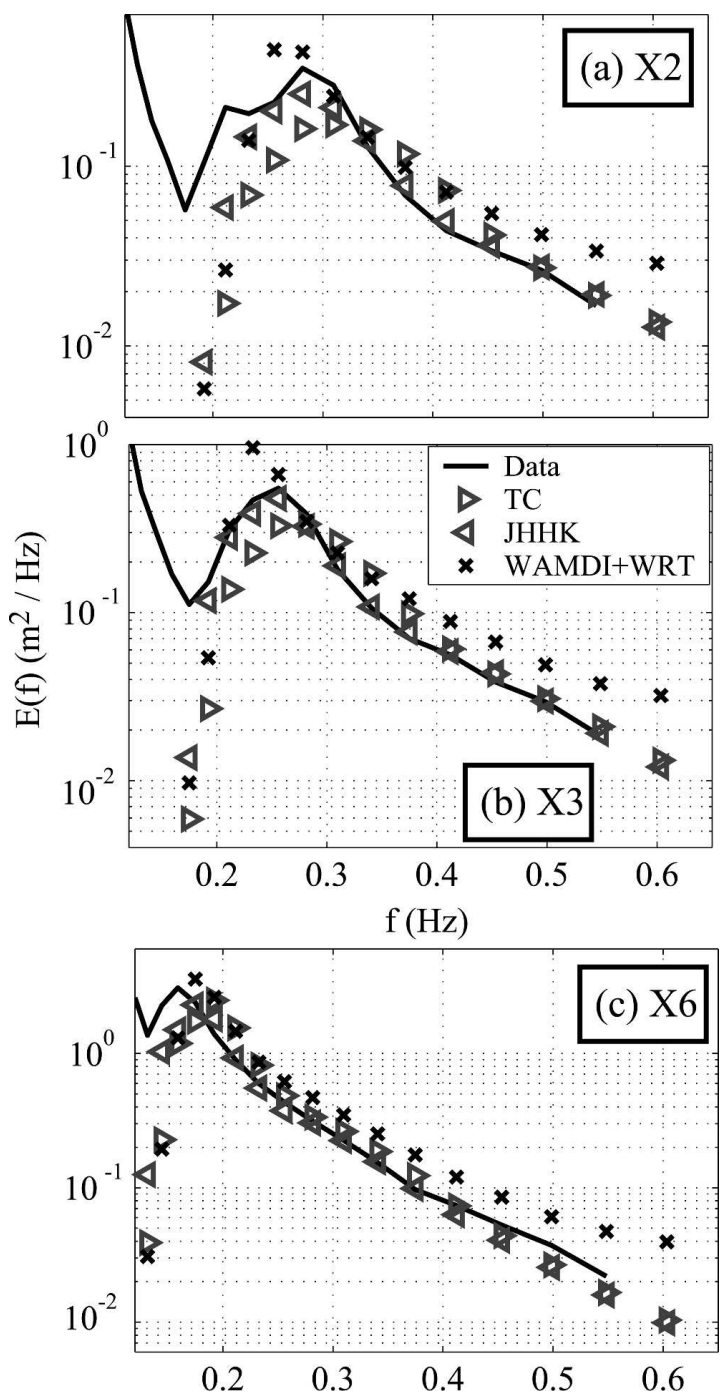

FIG. 10. Wave spectra on 3 Nov 1999, averaged over the 12001700 EST time window, from observations and model runs without swell and with different model settings (symbols): (a) on the inner shelf at buoy X2, (b) on the midshelf at X3, and (c) in deep water at X6.

obtained on the mid- and outer shelf for all source term parameterizations (Fig. 10). Indeed the wind wave height obtained with the BAJ and JHHK parameterizations differ by less than $6.5 \%$ and $13 \%$ from the observations, respectively. That latter number is comparable to the results typically obtained for short-term forecasts with the best wave models used on a global scale (Bidlot et al. 2007). The Wave Model Development and Implementation (WAMDI) and JHHK source terms lead to spectra that are slightly more energetic than those produced with the Tolman-Chalikov (TC) parameterization, in particular at short fetch (Figs. 10a,b). This underestimation of wave growth for short fetches by TC was reported earlier by Rogers
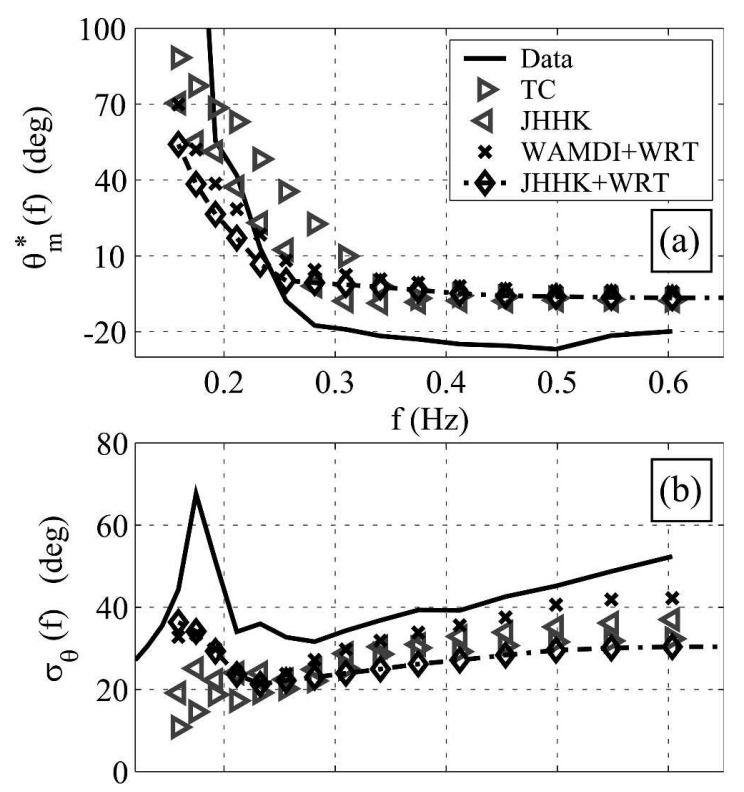

Fig. 11. Observed and modeled (a) mean direction and (b) directional spread at buoy X3. All parameters are derived from spectra averaged over the time window of 1200-1700 EST.

(2002). Although the parameterizations used here in WW3 or WAM were tuned for idealized wind wave growth, they give good predictions of the wind wave spectra, observed here in the presence of swell. Thus, the swell present at the time of our observations does not appear to significantly affect wind wave growth. The spectral shapes predicted with $S_{\mathrm{nl}}^{\mathrm{WRT}}$ differ more from the observations. This reflects the lack of retuning of the shapes of other source terms. Anomalously large energy levels at high frequency also suggest that the model setup is not optimal for integration with $S_{\mathrm{nl}}^{\mathrm{WRT}}$, either due to large time steps or too narrow a frequency range (van Vledder 2006).

Mean directions give complementary information. Comparisons with observations are now detailed for buoy X3, where model results are representative of the entire shelf. First of all, the directions of modeled and observed high-frequency waves at X3 are different (Fig. $11 \mathrm{a}, f>0.3 \mathrm{~Hz}$ ), suggesting that the local COAMPS wind prediction is likely $15^{\circ}$ off from the true wind direction. Based on the sensitivity analysis of wave growth on the wind direction (Fig. 8), this calls for the use of a more accurate wind field, which unfortunately was not available.

Although the forcing wind field may have significant errors, the same wind used with various source term combinations leads to striking differences in the mean directions for frequencies in the range $0.2<f<0.3 \mathrm{~Hz}$, around the wind-sea peak. The TC parameterization predicts waves propagating a $50^{\circ}$ (at X1) to $30^{\circ}$ (at X3) 

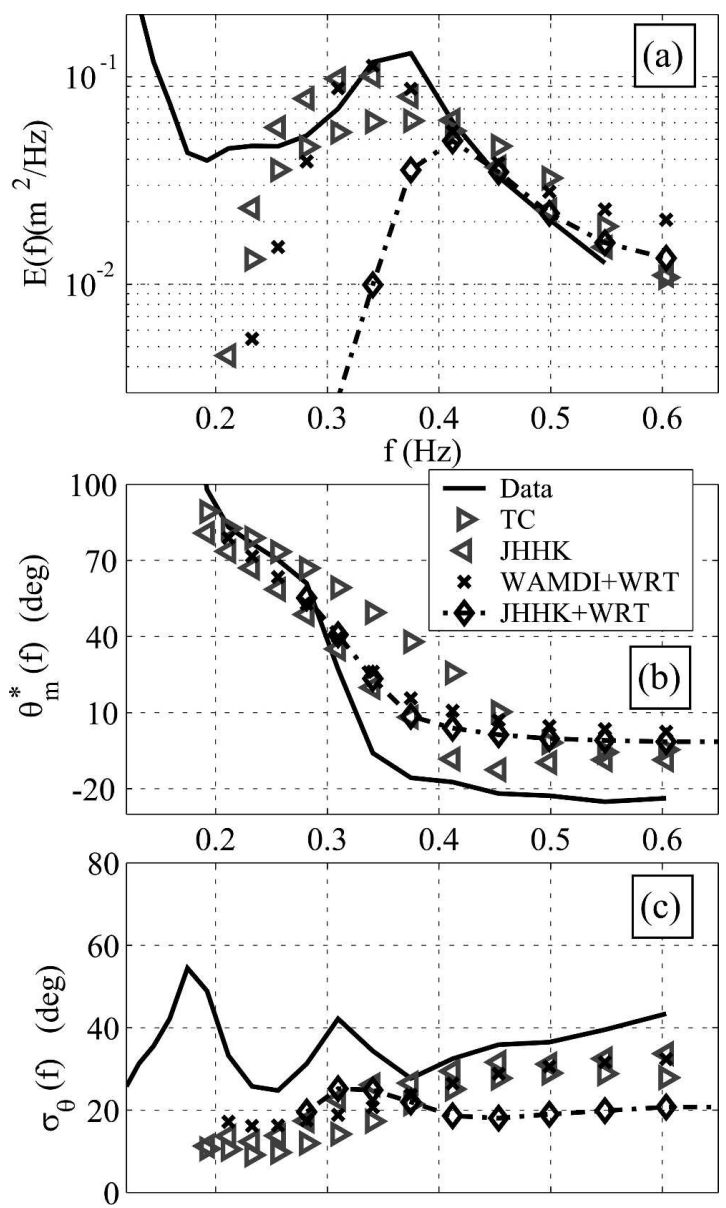

FIG. 12. Observed and modeled (a) frequency spectrum, (b) mean direction, and (c) directional spread at buoy X1. All parameters are derived from spectra averaged over the time window of 1300-1700 EST.

more oblique direction (from the north-northwest), while JHHK + WRT has waves propagating too close to the wind direction for $f<0.25 \mathrm{~Hz}$. This shift in direction reflects a different balance of source terms in TC, JHHK, and JHHK + WRT, which has not been analyzed before.

At shorter fetch, this difference is even larger. At X1, all model runs fail to represent the $0.2-0.3-\mathrm{Hz}$ plateau of energy in the wave spectrum with an abrupt shift in direction from $110^{\circ}$ at $0.27 \mathrm{~Hz}$ to $20^{\circ}$ at $0.33 \mathrm{~Hz}$ (Fig. 12). All model runs yield variations of the mean direction that are much smoother than the observations. Some of these model errors may be attributed to a model wind direction that differs by as much as $17^{\circ}$ from the observed wind in the area close to X1 (station DUCN7, Fig. 2). However, test runs with a uniform wind from $20^{\circ}$, close to the observed wind and mean high-frequency wave directions on the inner shelf, do not reproduce (not shown) this sharp separation in two wind-sea systems found at X1 (Fig. 12b) and FRFWR (Fig. 3). Below the wind-sea peak frequency, these test runs (both with JHHK and TC) yield $\theta_{m}^{*}(f)$ predictions that are within $10^{\circ}$ of the values shown here obtained with COAMPS wind fields. Thus, the wind field error does not explain the qualitative model errors.

Further information is finally given by the directional spread $\sigma_{\theta}$. Although buoy measurements are known to be erroneous below the peak frequency owing to nonlinearities in the wave field (Krogstad 2002), observations for $f_{p}<f<3 f_{p}$ are expected to be reliable (e.g., O'Reilly et al. 1996). The WAMDI + WRT parameterization yields the broadest directional spectra (Fig. 11b) compatible with observations, although still slightly too narrow. In contrast, JHHK + WRT produces spectra that are too narrow at high frequencies, and TC or JHHK (with the DIA) have similar yet smaller biases. High biases of $\sigma_{\theta}$ that were previously reported by Forristall and Ewans (1998) in WAM results are also found here in runs with the WAMDI parameterization (not shown), but are limited to about $5^{\circ}$. This bias is consistent with the known directional bias of the DIA (Hasselmann et al. 1985, their Fig. 12); namely, the DIA scatters wave energy at much larger oblique angles than is predicted for the exact nonlinear transfer.

The 1997 case offers another interesting example. In the absence of available high-resolution wind fields, the wind is assumed to have a steady band structure-uniform in the upwind $\left[-25^{\circ}\right.$, i.e., $225^{\circ} \mathrm{T}$ (relative to north)] direction and linearly varying in the crosswind direction from a maximum of $13 \mathrm{~m} \mathrm{~s}^{-1}$ at Diamond Shoals (station DSLN7) to $7 \mathrm{~m} \mathrm{~s}^{-1}$ at the Duck FRF pier (station DUCN7) with this value kept constant farther to the northwest (Fig. 13). Such a schematic wind field is nondivergent, matches observations at the coastal stations (Fig. 5), and is consistent with a band of clouds aligned in the $-25^{\circ}$ direction that can be seen in visible Geostationary Operational Environmental Satellite (GOES)-East satellite images (not shown). The model results will thus be qualitative.

Although there are differences in energy levels, all model runs have waves propagating at large angles to the wind at the SD97 array, in agreement with observations (Fig. 14a). Runs with a flat bottom reveal that refraction effects are weak at SD97 (Fig. 15) but are the main reason for the shift in wave direction at $8 \mathrm{M}$ and the accompanying strong reduction in energy between the two arrays (Fig. 14b). Runs with the WRT method for nonlinear interactions approximately reproduce the observed narrow spectra at high frequencies $(0.3<f<$ $0.5 \mathrm{~Hz}$ ) with a mean direction within $5^{\circ}$ of observations at $8 \mathrm{M}$, but a larger error up to $20^{\circ}$ at SD97.

Results of different models with different parameter- 


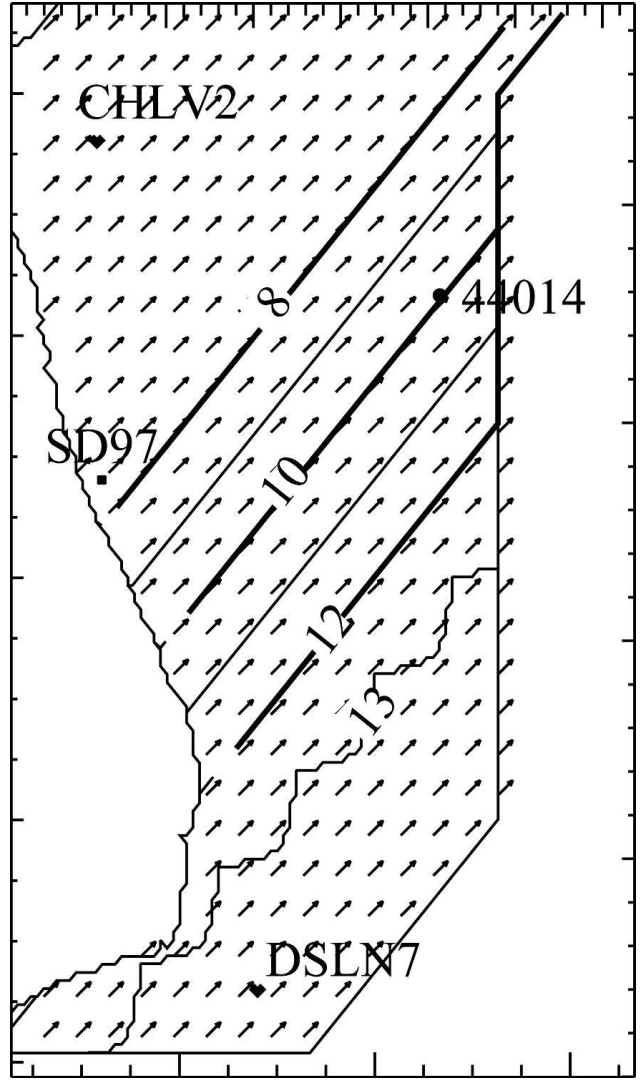

FIG. 13. Schematic wind field used for the model hindcast of waves for 17-18 Aug 1997. Contours indicate wind speeds and arrows show the wind direction.

izations, all using the same wind field, are compared in Fig. 15. Because of the proximity to land and related spatial advection scheme problems (appendix B), runs with the same parameterizations are shown for both models. The energy levels and directional width of the modeled spectra vary widely, from reasonable estimates with TC or WAMDI + WRT source terms to large overestimations when WAMDI is used (Fig. 15). This illustrates the sensitivity of wave growth predictions at slanting fetches to the directional distribution of the source terms, confirming that the WAMDI source term combination produces too much energy at large angles relative to the wind.

\section{d. Directional distribution of $S_{\text {in }}$}

The large differences between model results originate from the source term parameterizations, and thus may provide some insight into how the shape and magnitude of the source functions may be improved. The DIA is known to be less accurate than the WRT method. However, the directional spreads obtained with JHHK (i.e., using the DIA) are more realistic than those given by JHHK + WRT. In the 1999 event, the latter source term combination also leads to a strong underestimation of the wave energy at short fetch (Fig. 12a, dash-dotted line). These results suggest that the directional distribution of Janssen's (1991) wind wave growth parameter $S_{\text {in }}^{\mathrm{J}} / E$, which is proportional to $\cos ^{2}\left(\theta-\theta_{u}\right)$, is too narrow to generate enough energy at large angles away from the wind, and thus less energy accumulates along the slanting fetch than is observed (Fig. 12a). The parameterization $S_{\mathrm{nl}}^{\mathrm{DIA}}$ apparently compensates for this narrow wind input with spurious energy transfers to obliquely traveling waves. This conclusion on the directional width of $S_{\text {in }}$ assumes that no other unknown processes are active and that the isotropic directional distribution of the decay time scale $E / S_{\mathrm{ds}}$ is correct [which is contradicted by recent experimental estimates of $S_{\mathrm{ds}}$ by Young and Babanin (2006)]. A negative wind input for waves faster than the wind, as in $S_{\text {in }}^{\mathrm{TC}}$, does slightly reduce $\sigma_{\theta}$, but the magnitude of that effect, as represented in $S_{\mathrm{in}}^{\mathrm{TC}}$, is not sufficient to account for the present observations.

Comparing source terms and spectral shapes at X3 (Fig. 16) indicates that $S_{\text {in }}^{\mathrm{TC}}$ is quite broad at low frequencies. Furthermore, in the TC run, the maximum values of $S_{\mathrm{in}}$ and $S_{\mathrm{nl}}$ are about half of the values in the JHHK runs, while that of $S_{\mathrm{ds}}$ in TC is only $25 \%$ of the value in JHHK. This is true for the magnitude of the source term and, factoring out the fact that they correspond to different spectra, it is also true for the growth and decay rates (Fig. 17). The growth rate $S_{\text {in }}^{\mathrm{TC}} / E$ has a complex shape that resembles the $\cos ^{2}\left(\theta-\theta_{u}\right)$ of $S_{\text {in }}^{\mathrm{J}}$ for $\left|\theta-\theta_{u}\right|<30^{\circ}$ at high frequencies (Fig. 17a) and a broader shape at the wind-sea peak, close to that of $S_{\text {in }}^{\text {SDEL }}$ (Fig. 17b). The combination of a broad input and a relatively low dissipation explains the accumulation of energy along very oblique directions in TC, and the corresponding shift in mean direction at the wind-sea peak (Fig. 11a).

These different source term shapes result in widely different energy balances for the various parameterizations. In TC both wind input and nonlinear transfer contribute to the slanting-fetch energy. At large angles the wind input and dissipation are relatively weak, and the net source term is dominated by the nonlinear energy transfer (Fig. 18a), explaining the large directional shift at and below the peak frequency (Fig. 11a). In JHHK a similar nonlinear energy transfer at large angles is opposed by a strong dissipation so that the slanting-fetch energy is concentrated at smaller angles. The strong dissipation thus acts like a relaxation term, pulling the mean direction closer to the wind direction. In WAMDI + WRT both nonlinear transfer and dissipation have similar magnitudes in oblique directions (e.g., $\theta^{*}=50^{\circ}$ : see Fig. $18 \mathrm{c}$, note the different 

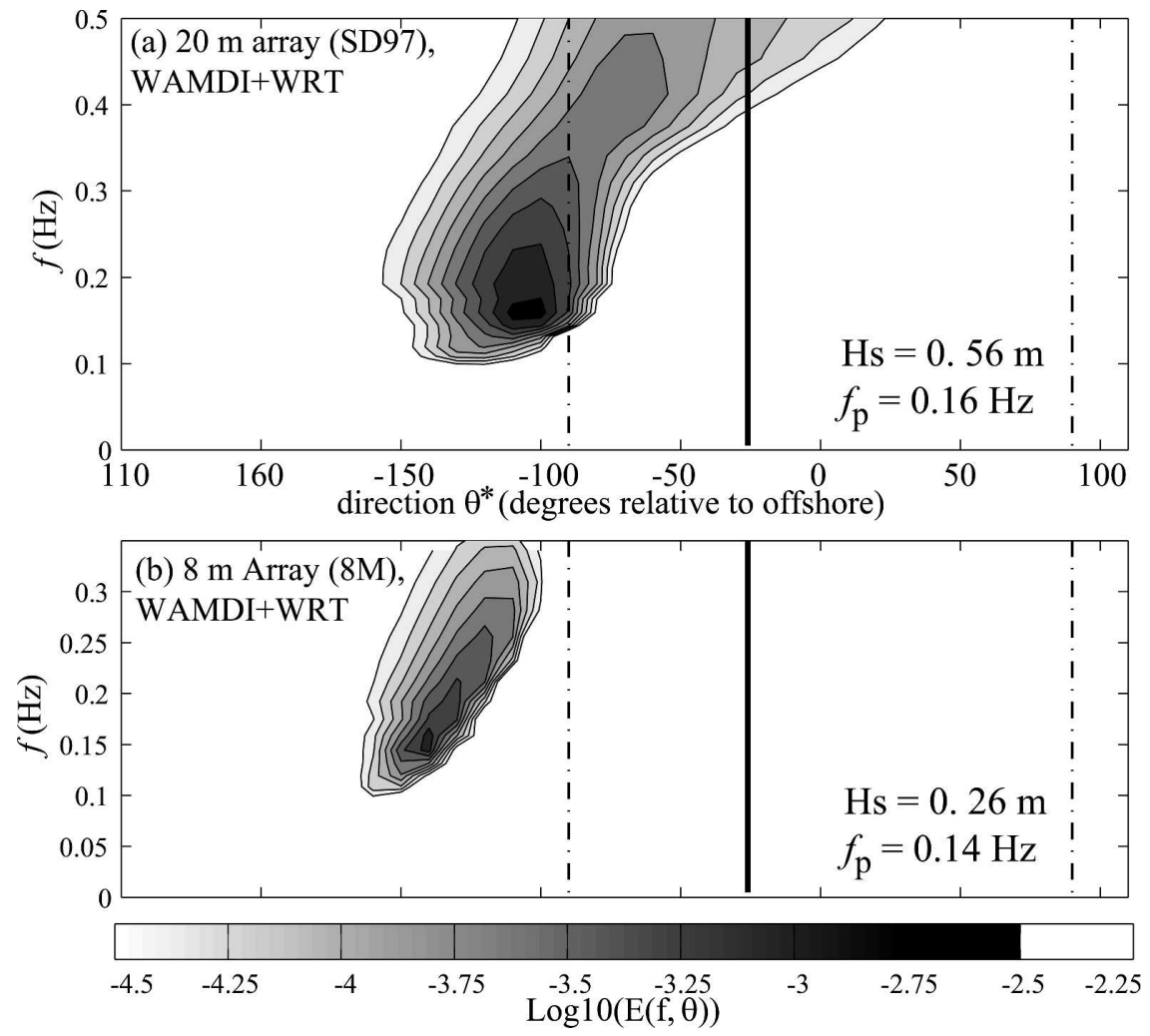

FIG. 14. As in Fig. 6, with predicted instead of observed wave spectra, on 17-18 Aug 1997 using the WAMDI + WRT parameterization in CREST.

vertical scales), resulting in directional properties of the wave field that are similar to the JHHK run (Figs. $12 \mathrm{~b}, \mathrm{c})$.

With this interpretation, the sharp transition of $\theta_{m}^{*}$ for $f=0.37 \mathrm{~Hz}$ at FRFWR and for $f=0.33 \mathrm{~Hz}$ at X1 suggests a shift from a part of the spectrum where the dissipation is weak, and likely better described by TC, to a higher frequency part with strong local generation and dissipation, better described by JHHK or WAMDI. This finding supports a transition in the mode of wave dissipation between low and high frequencies, as proposed by Tolman and Chalikov (1996), occurring at a frequency $f_{t} ; f_{p}$, lower than the value $f_{t} ; 2 f_{p}$ defined in $S_{\mathrm{ds}}^{\mathrm{TC}}$. Such a transition would be consistent with a decomposition between direct energy losses due to the breaking of waves of a given scale, and the indirect effect of turbulence. Indeed, Banner et al. (2002) and Melville and Matusov (2002) have shown that waves at the peak frequency do break, although less frequently with increasing wave age.

This conclusion is robust to errors in the wind forcing because the JHHK run with a wind rotated by $20^{\circ}$ (not shown) gives values of $\theta_{m}^{*}$ that are within $10^{\circ}$ of those obtained with the COAMPS winds at X2 and X1, but still $15^{\circ}$ and $30^{\circ}$ more oblique than observed values at $\mathrm{X} 2$ and $\mathrm{X} 1$, respectively.

\section{e. Hindcasts with both wind waves and swell}

Our comparisons of model results with observations are meaningful only if swell does not impact significantly the growth of the wind sea. The swell was omitted to avoid known deficiencies of the WAMDI and JHHK parameterizations when wind seas are generated in the presence of swell (e.g., Tolman and Chalikov 1996; Booij and Holthuijsen 2002). The interactions between wind waves and swell in the various models are considered now. Since recent modeling efforts have led to better wave height and peak period forecasts on a global scale using the BAJ parameterization (Janssen et al. 2005; Ardhuin 2006), this parameterization is also tested. The offshore frequency-direction wave spectra for 1999 were estimated from buoy X6. The observed offshore swell is now added as a boundary condition.

On one hand, adding wind forcing does not change significantly the swell prediction. There is a weak tendency of WAMDI and JHHK source terms to enhance the swell attenuation, as reported by Rogers et al. (2003), but it is hardly visible here (Fig. 19b) owing to 

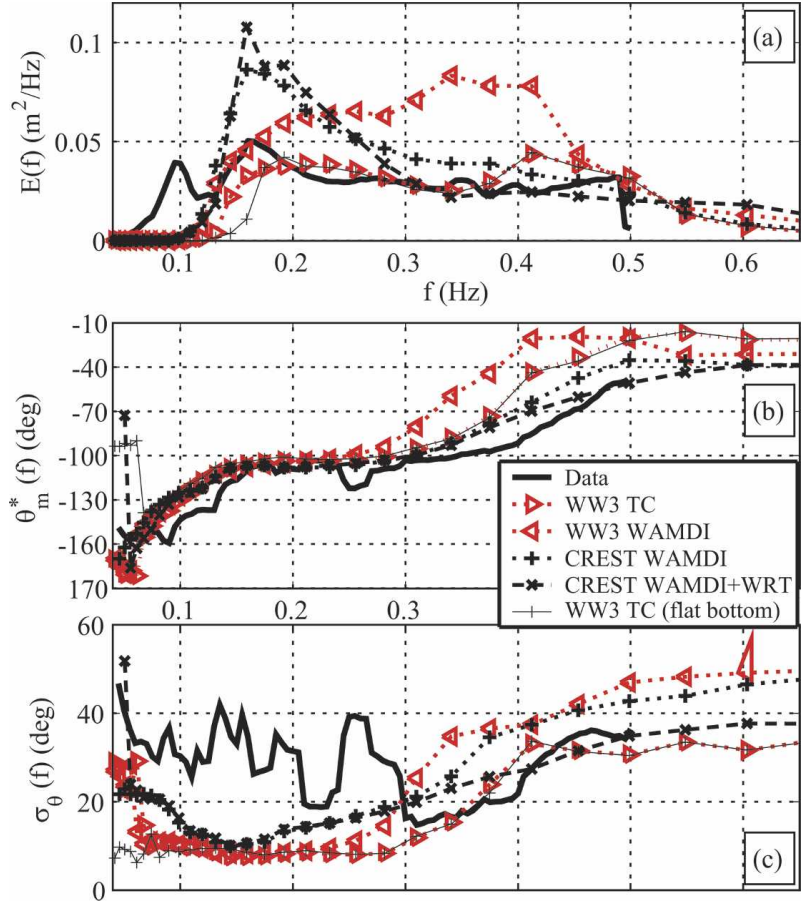

FIG. 15. Comparison of observed and predicted (a) frequency spectra, (b) mean direction, and (c) directional spread at the SD97 array (same time interval as that in Fig. 6).

the short propagation distance. On the other hand, in some model results the wind sea is strongly affected by the introduction of swell. Using the WAMDI parameterization, the relative dissipation $S_{\mathrm{ds}} / E$ at $\mathrm{X} 3$ is reduced by a factor of 2 at $f=0.26 \mathrm{~Hz}$. This reduced dissipation arises from a smaller value of the mean steepness based on the mean wavenumber $k_{-0.5}$ (appendix A), which is quite sensitive to low frequency energy. As a result, the wave field is more developed (cf. Figs. 19b and 10b). This effect is less pronounced with JHHK, for which the high-frequency tail is closer to the observations, but it is still significant. The increased wave growth in the presence of swell, given by WAMDI and JHHK, has no physical basis and clearly indicates a deficiency of the parameterization (Janssen et al. 2005). To the contrary, the wind-sea growth in TC is only weakly influenced by the swell, in agreement with the present observations.

The spurious swell effect in models of wind wave growth was described earlier by Booij and Holthuijsen (2002, and references therein), who showed that $S_{\text {tot }}^{\text {WAMDI }}$ gave relatively good agreement with laboratory observations of wind waves opposing mechanically generated waves, while it failed to reproduce the suppression of wind-sea growth observed in the laboratory for following swells (Phillips and Banner 1974; Donelan 1987). The agreement with one experiment and disagreement with the other is purely fortuitous as the relevant processes are not accounted for in either WAMDI or JHHK (see section 2a). A more physical discussion of the problem, with a proposed solution and first validation with field data, is given by van Vledder and Hurdle (2002).

The presence of swell with WAMDI or JHHK also modifies the mean directions at low frequencies and short fetches, giving more oblique wave directions (Fig. 19a), as the weaker dissipation reduces the relaxation to the wind direction (section 4b). This effect is small at X3 (Fig. 19c) and farther offshore. In contrast, the directional spread for frequencies above the peak is strongly affected by swell throughout the shelf with the JHHK and WAMDI parameterizations. This result is quite similar to the effect of dissipation, discussed by Banner and Young (1994), with broader spectra when the dissipation is lower. Too much energy is apparently pumped at large angles away from the wind by the DIA, and that spurious energy transfer is not properly balanced by dissipation in the presence of swell, resulting in anomalously broad spectra (Fig. 19d). Last, the use of a mean steepness computed from $k_{0.5}$ in $S_{\mathrm{ds}}^{\mathrm{BAJ}}$ instead of $k_{-0.5}$ (appendix A) does not reduce much the effect of the swell on the wind sea (Fig. 20).

Differences between the model runs are summarized by the energy growth curves (Fig. 21). The best fit for the total wind-sea energy is given by the BAJ parameterization in the absence of swell. However, this parameterization still overestimates the wind-sea energy by about $50 \%$ in the presence of swell for short fetches $\left(X^{*}<6 \times 10^{3}\right)$.

\section{Conclusions}

Observations reported here generally support previous findings that a moderate swell opposing the wind does not significantly impact wind wave growth in the ocean. For moderate angles $\left(20^{\circ}-30^{\circ}\right)$ between the wind and shore-normal direction, the observed windsea evolution agrees well with wave height and period growth curves obtained by Kahma (1981) for similarly unstable atmospheric conditions and moderate wind angles relative to shore normal. In all cases, significant wave energy is found to propagate in directions as large as $75^{\circ}$ relative to the wind, even when depth-induced refraction is negligible.

The wave energy is generally well reproduced by model runs that exclude swell and neglect the effects of air-sea stability. The stability correction of Tolman (2002b) slightly improves the hindcast that uses the parameterization of Tolman and Chalikov (1996). Model results that include both swell and wind waves clearly show that the parameterizations proposed by the 

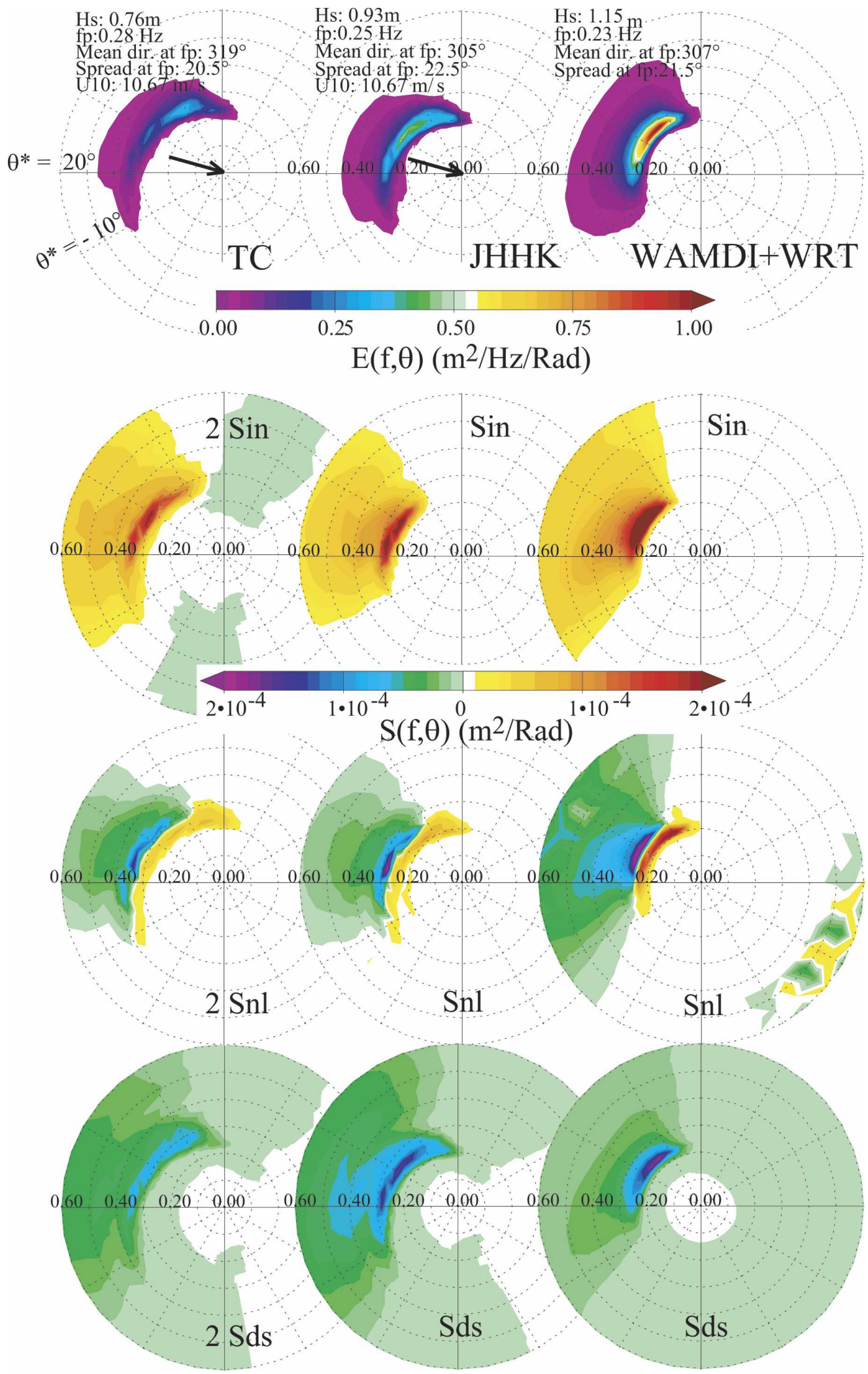

FIG. 16. Spectra and source terms at X3 for the three parameterizations: TC, JHHK and WAMDI + WRT. Arrows indicate the local wind direction. Note that TC source terms were multiplied by 2 in order to be on a comparable scale. Directions $\theta$ are standard nautical directions relative to true north (directions from) and the conversion of $\theta$ to shore-normal-relative $\theta^{*}$ is indicated in the top-left panel. 

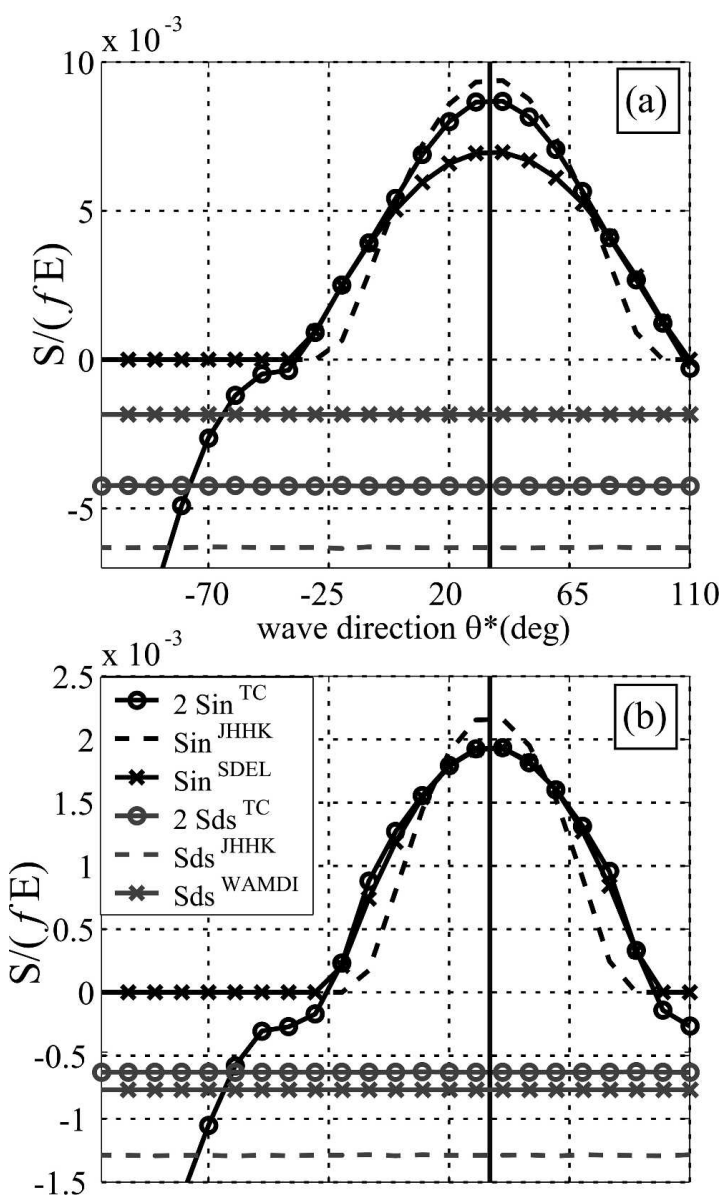

FIG. 17. Directional shapes of the wind input and dissipation source terms at (a) $f=0.66 \mathrm{~Hz}$ and (b) $f=0.26 \mathrm{~Hz}$. Note that TC source terms were multiplied by a factor of 2 in order to make the curves more easily comparable. The source terms are normalized by the spectrum $E$ and the frequency $f$ to give nondimensional growth or decay rates. The thick vertical line indicates the model wind direction.

WAMDI Group (1988), and, to a lesser degree, Janssen et al. (1994), are not well adapted to this very common type of sea state. In these parameterizations $S_{\mathrm{ds}}$ is proportional to an overall mean wave steepness that is very sensitive to the presence of swells, which is not supported by field observations. A corrected parameterization by Bidlot et al. (2007) reduces, but does not eliminate, the spurious effect of swells on wind wave generation. Further improvement will likely require a proper separation between wind-sea dissipation and swell dissipation, such as proposed by Tolman and Chalikov (1996), and/or a dissipation parameterization that is a weaker function (e.g., Donelan 2001; van Vledder and Hurdle 2002), or not a function at all (e.g., van der Westhuysen et al. 2007), of the energy at lower frequencies. The latter parameterization leads to good results for hindcasts of the SHOWEX event discussed here
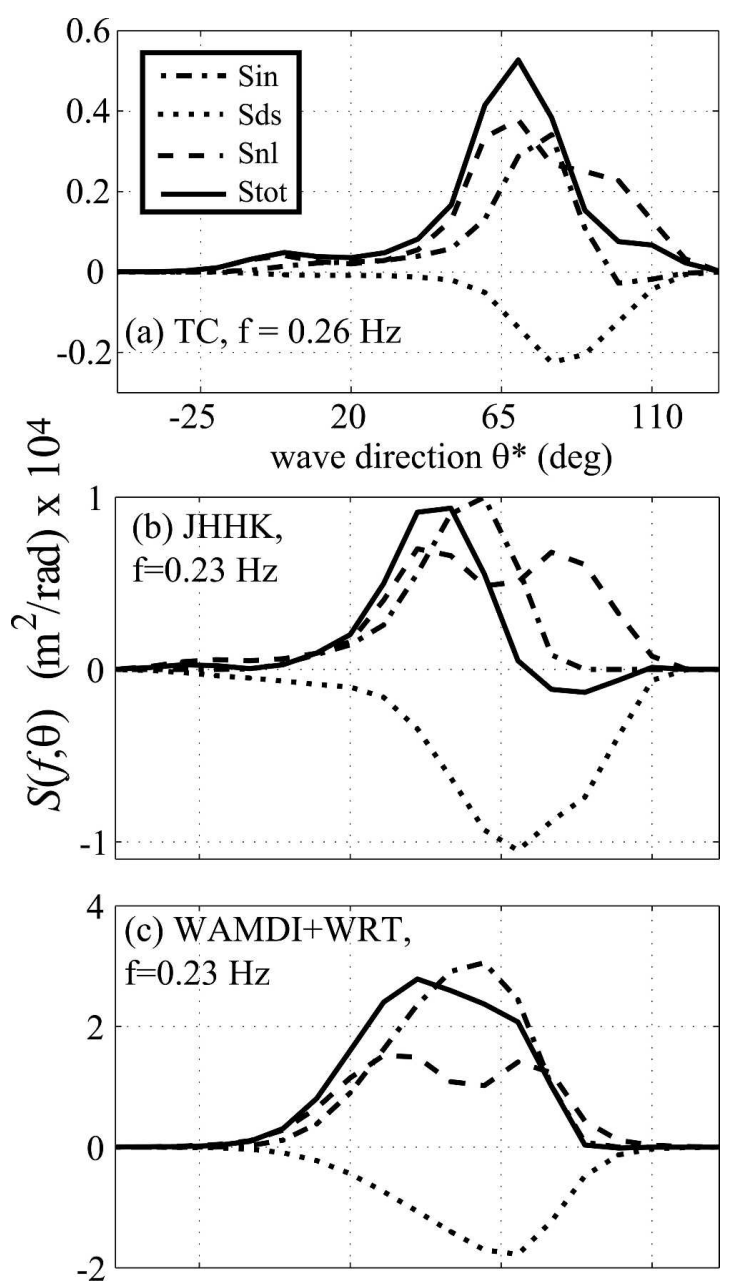

FIG. 18. Balances of source terms at $\mathrm{X} 3$ on the forward (low frequency) face of the wind-sea spectrum: $S_{\text {in }}$ (dash-dot line), $S_{\mathrm{ds}}$ (dotted line), $S_{\mathrm{nl}}$ (dashed line), and the sum of all three (solid line).

(not shown). However, it also gives an order of magnitude too large dissipation at low frequencies, resulting in a low bias of the order of $40 \%$ for wave heights in the North Atlantic (Ardhuin and Le Boyer 2006).

The present wave observations are more novel in their directional properties. For the shortest fetch $\left(X^{*} \leq\right.$ 2000 ), the wind sea is clearly separated into two wave systems. The lower frequency system propagates alongshore in the direction of the slanting fetch, while the higher frequency system propagates downwind. Although the total wind-sea energy agrees with Kahma's (1981) growth curve, the energy of the high frequency downwind system is closer to the JONSWAP growth curve (Hasselmann et al. 1973). Observed wave spectra reveal a sharp transition between these two wave systems, with a $90^{\circ}$ shift in the direction $\theta_{m}^{*}(f)$ at approximately the peak frequency. The observed values of 

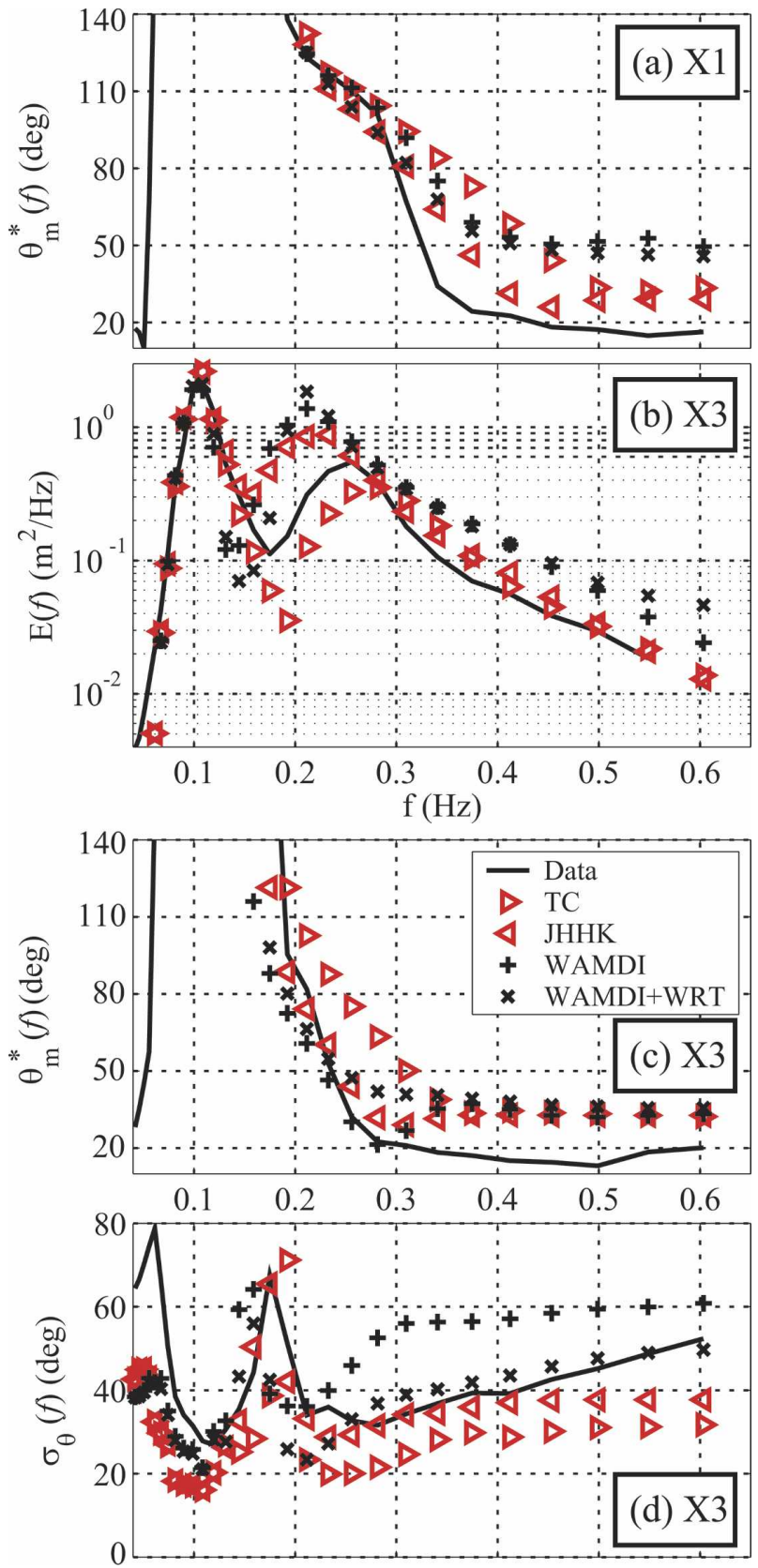

FIG. 19. Observed and modeled (a) mean direction at buoy X1, (b) frequency spectrum, (c) mean direction, and (d) directional spread at buoy X3. All parameters are derived from spectra averaged over the time window of 1300-1700 EST.

$\theta_{m}^{*}(f)$ provide a useful diagnostic of the source term balance in wave prediction models. Although the wind fields used here contain some uncertainties, the wind input term of Janssen (1991) is found to be too narrow in direction, at least at the peak frequency, while the forms proposed by Snyder et al. (1981) and Tolman and Chalikov (1996) have a more appropriate directional shape in that range.

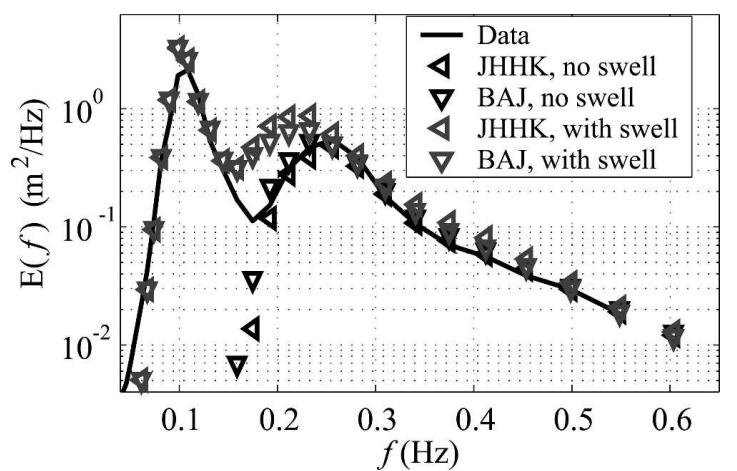

FIG. 20. Wave spectra computed with and without swell at 1300 1700 EST 3 Nov 1999 at buoy X3, using JHHK and the correction BAJ proposed by Bidlot et al. (2007).

However, the generally weaker input and nonlinear terms of Tolman and Chalikov (1996) require an even weaker dissipation near the peak frequency to yield a similar wave growth. In slanting-fetch situations, this weaker dissipation causes a shift of the mean direction to the alongshore direction that is less pronounced in the present observations of $\theta_{m}^{*}\left(f_{p}\right)$, even when errors on the model wind direction are considered. A somewhat better agreement is found using the source terms of Janssen et al. (1994). The observed values of $\theta_{m}^{*}(f)$ support a transition from weak dissipation for $f<f_{p}$ to a stronger dissipation for $f>f_{p}$, instead of the transition at $f \simeq 2 f_{p}$ hypothesized by Tolman and Chalikov (1996). Saturation-based dissipation theories (e.g., Phillips

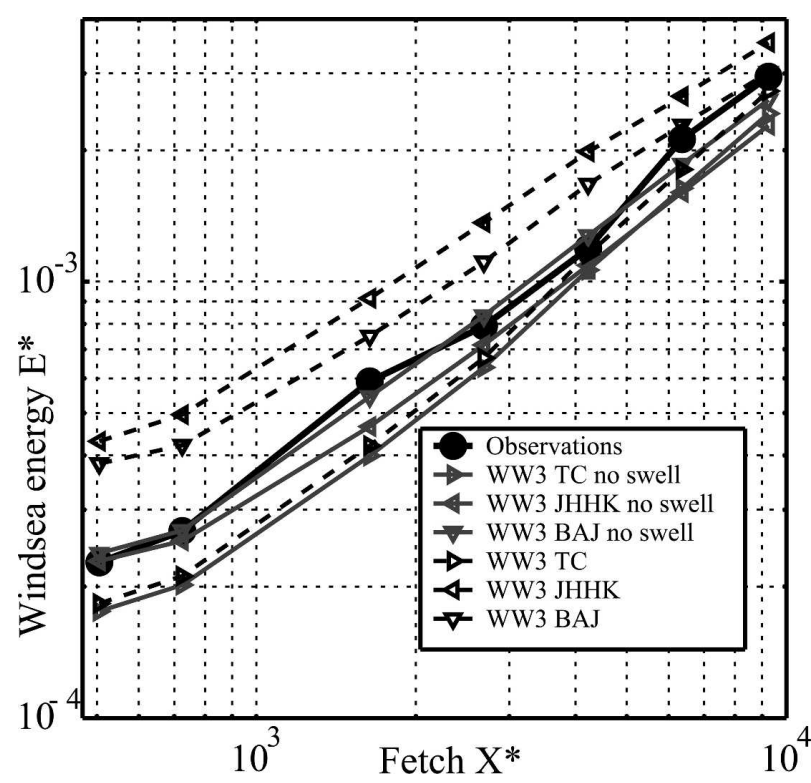

FIG. 21. Cross-shelf evolution of dimensionless wind-sea energy given by WAVEWATCH III for several parameterizations using COAMPS winds, neglecting the effects of air-sea stability. 
1985; Alves and Banner 2003) are one alternative for improving the description of wave breaking effects on high-frequency waves, but they must be combined with a physically sound description of swell dissipation that is yet to be fully tested [e.g., Kudryavtsev and Makin (2004), taking into account the criticism of the inner layer depth by Janssen (2004)]. A preliminary analysis of the 3 November event provides an upper bound of $\beta=-5 \times 10^{-5}$ for the fractional decay per radian of 10 -s swells due to opposing winds, based on a maximum attenuation of $30 \%$ of the observed energy, compared to the prediction taking into account refraction only. This maximum estimate is of the order of the attenuation predicted by Kudryavtsev and Makin (2004) for the present conditions. A wider variety of field data with nonclassical spectra shapes, for example, in the presence of larger swells and turning winds, is needed to better constrain the shape and magnitude of the wind generation and dissipation terms.

In practice, improvement of the source term balance in wind wave models is hampered by the computational cost of an accurate estimation of the nonlinear interactions, and the widely used discrete interaction approximation (DIA) only crudely describes the full spectral interactions in complex sea states. To examine the role of wave-wave interactions in the evolution of the directional wave properties and the associated errors in the DIA, the full Boltzmann integral of nonlinear interactions $S_{\mathrm{nl}}$ was evaluated here using the same, relatively coarse, spectral discretization. This computation was feasible here thanks to the relatively small number of grid points used in the nonstructured grid of the CREST model. This type of grid, also used in other models (e.g., Benoit et al. 1996; Hsu et al. 2005), makes the exact calculation within reach of today's computing resources for operational forecasting in coastal areas. Good agreement between WAVEWATCH III and CREST predictions using the same source terms confirms that numerical errors in the advection schemes are generally small. The Tolman and Chalikov's (1996) set of source terms uses the DIA with a reduced interaction coefficient. This leads to a very different source term balance at short fetch, with strong biases in the mean wave direction. For the quasi-steady cases analyzed, the wind input and dissipation in the source term combinations of Janssen et al. (1994) and Bidlot et al. (2007) largely cancel errors of the DIA, namely, an overestimation of the growth of low-frequency waves and excessive broadening of the directional spectrum.

Acknowledgments. This research is supported by the Coastal Geosciences Program of the U.S. Office of Naval Research. SHOWEX buoys X1-X6 and the Sandy-
Duck (SD97) array were deployed by staff from the Naval Postgraduate School and the Scripps Institution of Oceanography Center for Coastal Studies. ASIS buoys were deployed by RSMAS, and data was processed by Will Drennan. We thank W. C. O'Reilly for his contribution to SHOWEX and many helpful discussions. Data from the 8-m-depth $(8 \mathrm{M})$ array were provided by the Field Research Facility of the U.S. Army Corps of Engineers Waterways Experiment Station's Coastal Engineering Research Center. Data from other buoys and stations were provided by the National Data Buoy Center.

\section{APPENDIX A}

\section{The KHH Family of Parameterizations for Wave Dissipation}

$\mathrm{KHH}$ obtained realistic wave growth behavior in deep water with an adjusted form

$$
S_{\mathrm{ds}}^{\mathrm{KHH}}(\mathbf{k})=-g^{1 / 2} C_{\mathrm{ds}}\left(\frac{\bar{\alpha}}{\bar{\alpha}_{P M}}\right)^{2} \frac{k}{k_{0.5}} E(\mathbf{k}),
$$

where $C_{\mathrm{ds}}$ is a nondimensional empirical constant; $\bar{\alpha}$ is a mean steepness parameter that characterizes the overall intensity of wave breaking and was defined by $\mathrm{KHH}$ as $\bar{\alpha}=E_{\mathrm{tot}} k_{0.5}^{2}$, where $E_{\mathrm{tot}}=\int E(\mathbf{k}) d \mathbf{k}$, and the mean wavenumber $k_{x}$ is

$$
k_{x}=\frac{1}{E_{\mathrm{tot}}}\left[\int E(\mathbf{k}) k^{x} d \mathbf{k}\right]^{1 / x} .
$$

The constant $\bar{\alpha}_{\mathrm{PM}}=4.57 \times 10^{-3}$ is the value of $\bar{\alpha}$ for a Pierson-Moskowitz (Pierson and Moskowitz 1964) spectrum.

For reasons of numerical stability (Janssen et al. 2005), $\bar{\alpha}$ was replaced by $\hat{\alpha}=E_{\text {tot }} k_{-0.5}^{2}$, for what was later known as Cycle 3 of WAM (WAMDI Group 1988), in which dissipation was tuned so that the model using the DIA and $S_{\mathrm{in}}^{\mathrm{SDEL}}$, would reproduce observed wave growth in fetch-limited conditions. The corresponding dissipation is

$$
S_{\mathrm{ds}}^{\mathrm{WAMDI}}(\mathbf{k})=-g^{1 / 2} C_{\mathrm{ds} 3}\left(\frac{\hat{\alpha}}{\hat{\alpha}_{\mathrm{PM}}}\right)^{2} \frac{k}{k_{-0.5}} E(\mathbf{k}) .
$$

This unfortunate change means that, for equal energies, low-frequency waves have a larger effect on the total dissipation than high-frequency waves, although they contribute little to the actual surface slope. This parameterization has lead to spurious effects when both swell and wind waves are present (Tolman and Chalikov 1996; Rogers 2002; see section 4). The mean wavenumber $k_{-0.5}$ is also employed in the dissipation term $S_{\mathrm{ds}}^{\mathrm{JHHK}}$ of Janssen et al. (1994) and other forms of $S_{\mathrm{ds}}$ (Alves 

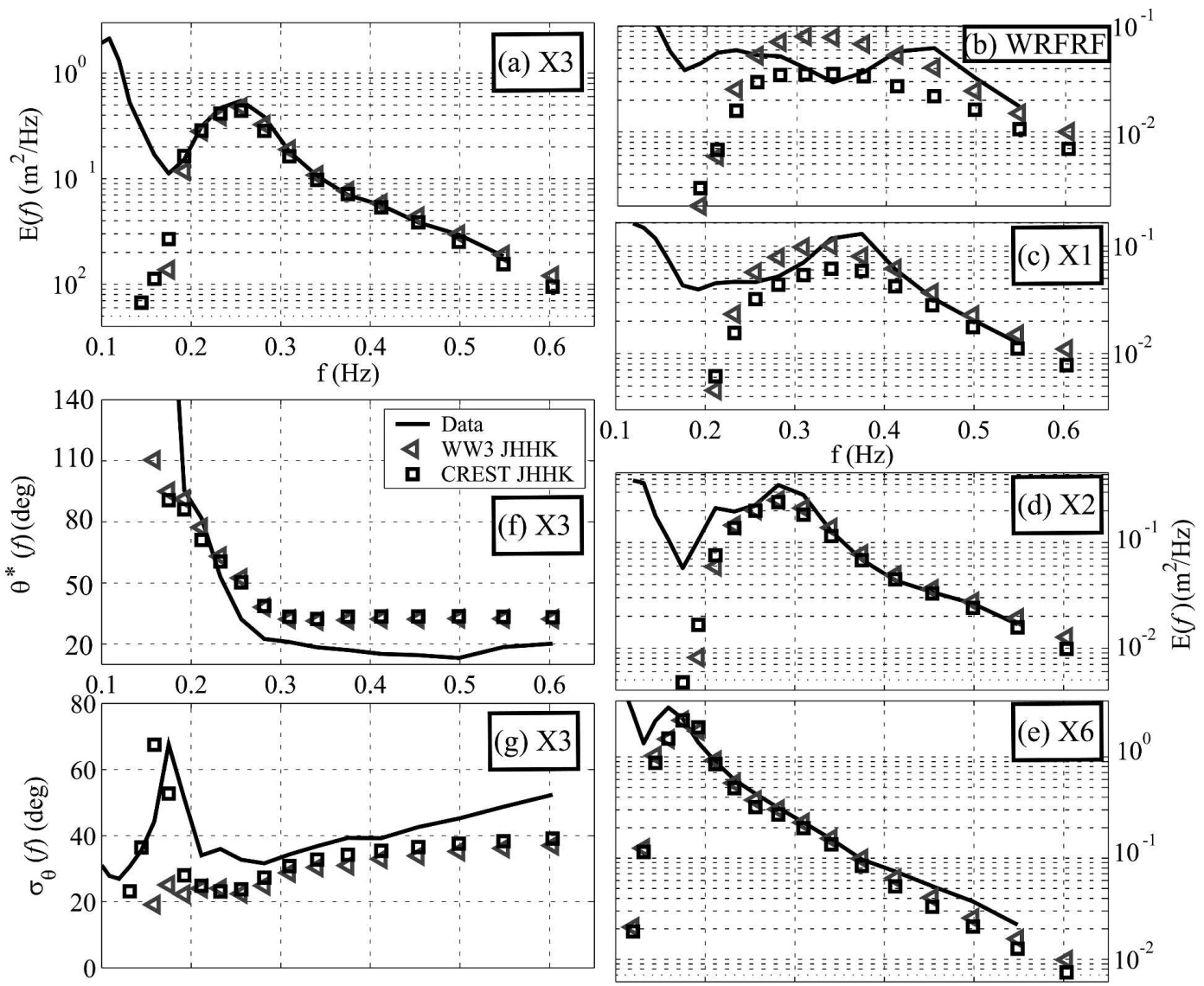

Fig. B1. (a)-(e) Frequency spectra at buoys X3, FRFWR, X1, X2, X6, and both as a function of frequency (f) mean directions and (g) directional spreads at X3, on 3 Nov 1999 (averages over the 1200-1700 EST time interval).

and Banner 2003). Here $S_{\mathrm{ds}}^{\mathrm{JHK}}$ was tuned for the WAM Cycle-4 model that uses $S_{\mathrm{nl}}^{\mathrm{DIA}}$ and $S_{\mathrm{in}}^{\mathrm{J}}$,

$$
S_{\mathrm{ds}}^{\mathrm{JHHK}}(\mathbf{k})=-C_{\mathrm{ds} 4}\left(\frac{\hat{\alpha}}{\hat{\alpha}_{P M}}\right)^{2}\left[0.5 \frac{k}{k_{-0.5}}+0.5\left(\frac{k}{k_{-0.5}}\right)^{2}\right] E(\mathbf{k}) .
$$

Only recently, Bidlot et al. (2007) reverted to the use of $k_{0.5}$ instead of $k_{-0.5}$, giving the source term

$$
S_{\mathrm{ds}}^{\mathrm{BAJ}}(\mathbf{k})=-C_{\mathrm{BAJ}} \bar{\alpha}^{2}\left[0.4 \frac{k}{k_{0.5}}+0.6\left(\frac{k}{k_{0.5}}\right)^{2}\right] E(\mathbf{k}) .
$$

This expression, like $S_{\mathrm{ds}}^{\mathrm{KHH}}$, gives a larger relative weight to the high frequency part of the spectrum, although much less so than other forms based on theoretical arguments of short wave straining by long waves (e.g., Donelan 2001; van Vledder and Hurdle 2002).

\section{APPENDIX B}

\section{Numerical Scheme in CREST and Comparison with WW3}

\section{a. Source term integration}

Potential numerical instabilities of the ray-based advection scheme with strongly nonlinear source terms are avoided by interpolating the sum $S_{\mathrm{in}}+S_{\mathrm{nl}}+S_{\mathrm{ds}}$ after integration over the global time step, using the dynamic adaptive time step scheme of WW3. This explicit integration is combined with an implicit integration of the other two terms, $S_{\text {bscat }}+S_{\text {bfric }}$ (Ardhuin and Herbers 2002). The maximum frequency of $0.73 \mathrm{~Hz}$ is not optimal for an accurate calculation of $S_{\mathrm{nl}}^{\mathrm{WRT}}$ (van Vledder 2006); it is a necessary compromise for an acceptable computation time while leading to errors in the estimation of $S_{\mathrm{nl}}$ for $f>0.6 \mathrm{~Hz}$. For this reason the integration of $S_{\mathrm{nl}}+S_{\mathrm{in}}+S_{\mathrm{ds}}$ was modified when $S_{\mathrm{nl}}^{\mathrm{WRT}}$ is used, with the diagnostic tail being applied starting one discrete frequency lower compared to the standard WW3 scheme. 


\section{b. Models' efficiency}

WW3 and CREST were both run on the same computer. Since CREST is not parallelized, the model performance may be compared when using a single processor. A 24-h hindcast using the DIA took $0.45 \mathrm{~h}$ of CPU) time with WW3 and $0.43 \mathrm{~h}$ with CREST (this calculation also includes bottom friction and scattering). Using $S_{\mathrm{nl}}^{\mathrm{WRT}}$ in CREST increases the CPU time to $48 \mathrm{~h}$. This increase of only a factor of 100 when changing from $S_{\mathrm{nl}}^{\mathrm{DIA}}$ to $S_{\mathrm{nl}}^{\mathrm{WRT}}$ (as compared with a factor of 300 for a single-point version of WW3) reflects the fact that when $S_{\mathrm{nl}}^{\mathrm{DIA}}$ is used in CREST, most of the CPU effort goes to the spectral advection and source term interpolation. It thus appears that using $S_{\mathrm{nl}}^{\mathrm{WRT}}$ is or will be feasible in the near future for coastal forecasting since a speed up by a factor of 20 can be easily achieved with a parallelization of CREST or the use of a more powerful computer system. This capability arises from the relatively small number of wet points (820 in CREST as compared with 9603 in WW3) and the use of relatively large time steps for the source term integration in both models. However, it is yet unclear that the increase in computational effort is warranted given the uncertainty in the other source terms. A balance must be found between the cost of the computation and its accuracy (e.g., Polnikov and Farina 2002).

\section{c. Models' results}

WW3 and CREST with the same total source term $S_{\text {tot }}^{\mathrm{JHHK}}$ yield nearly identical predictions of the frequency spectrum, mean direction, and direction spread (Fig. B1). The difference in wave-bottom interaction terms between the two models was also verified to have no effect on the wind sea. However, close to shore (Figs. B1b,c) discrepancies between the results of WW3 and CREST suggest numerical advection errors, not too surprisingly as FRFWR is located only two grid cells and two time steps from the coast. It is likely that the CREST scheme, with a linear interpolation of source terms on the rays over a 10 -min time step, is incompatible with the rapid variation of the spectrum and source terms at such a short fetch.

This first detailed test of CREST for wind-sea evolution confirms the consistency of the numerical advection schemes (the only important difference between the two models) and allows comparisons of CREST and WW3 with different source terms.

\section{REFERENCES}

Abdalla, S., and J. Bidlot, 2002: Wind gustiness and air density effects and other key changes to wave model in CY25R1.
ECMWF Research Department Tech. Rep. Memo. R60.9 SA/0273, 12 pp.

- and L. Cavaleri, 2002: Effect of wind variability and variable air density on wave modelling. J. Geophys. Res., 107, 3080, doi:10.1029/2000JC000639.

Alves, J. H. G. M., and M. L. Banner, 2003: Performance of a saturation-based dissipation-rate source term in modeling the fetch-limited evolution of wind waves. J. Phys. Oceanogr., 33, 1274-1298.

Anctil, F., M. Donelan, W. Drennan, and H. Graber, 1994: Eddycorrelation measurements of air-sea fluxes from a discus buoy. J. Atmos. Oceanic Technol., 11, 1144-1150.

Ardhuin, F., 2006: Quelles mesures pour la prévistion des états de mer en zone côtiere? Communications de Conf. l'Atelier Experimentation et Instrumentation, Brest, France, IFREMER and Cosponsors, 1-6. [Available online at http://www. ifremer.fr/aei2006/resume_long/T1S3/14-aei2006-55.pdf.]

— surface gravity waves by irregular sea bed topography. $J$. Fluid Mech., 451, 1-33.

— prediction models resolve directional spread? J. Atmos. Oceanic Technol., 22, 883-892.

— , and A. D. Jenkins, 2005: On the effect of wind and turbulence on ocean swell. Proc. 15th Int. Polar and Offshore Engineering Conf., Vol. III, Seoul, South Korea, ISOPE, 429434

— , and — 2006: On the interaction of surface waves and upper ocean turbulence. J. Phys. Oceanogr., 36, 551-557.

_- and A. Le Boyer, 2006: Numerical modelling of sea states: Validation of spectral shapes (in French). Navigation, 54, 5571.

— T. H. C. Herbers, and W. C. O'Reilly, 2001: A hybrid Eulerian-Lagrangian model for spectral wave evolution with application to bottom friction on the continental shelf. $J$. Phys. Oceanogr., 31, 1498-1516.

$\longrightarrow,-$, P. F. Jessen, and W. C. O'Reilly, 2003a: Swell transformation across the continental shelf. Part II: Validation of a spectral energy balance equation. J. Phys. Oceanogr., 33, 1940-1953.

_ W. C. O'Reilly, T. H. C. Herbers, and P. F. Jessen, 2003b: Swell transformation across the continental shelf. Part I: Attenuation and directional broadening. J. Phys. Oceanogr., 33, 1921-1939.

Banner, M. L., and I. R. Young, 1994: Modeling spectral dissipation in the evolution of wind waves. Part I: Assessment of existing model performance. J. Phys. Oceanogr., 24, 15501570.

— J. R. Gemmrich, and D. M. Farmer, 2002: Multiscale measurement of ocean wave breaking probability. J. Phys. Oceanogr., 32, 3364-3374.

Barnett, T. P., and A. J. Sutherland, 1968: A note on an overshoot effect in wind-generated waves. J. Geophys. Res., 73, 68796885.

Battjes, J. A., T. J. Zitman, and L. H. Holthuijsen, 1987: A reanalysis of the spectra observed in JONSWAP. J. Phys. Oceanogr., 17, 1288-1295.

Benoit, M., F. Marcos, and F. Becq, 1996: Development of a third generation shallow-water wave model with unstructured spatial meshing. Proc. 25th Int. Conf. on Coastal Engineering, Orlando, FL, ASCE, 465-478. 
Bidlot, J., P. Janssen, S. Abdalla, 2007: A revised formulation of ocean wave dissipation and its model impact. ECMWF Tech. Rep. Memo. 509, 29 pp.

Booij, N., and L. Holthuijsen, 2002: The effects of swell and wave steepness on wave growth and depth-induced wave breaking. Proc. Seventh Int. Workshop on Wave Forecasting and Hindcasting, Banff, AB, Canada, Meteorological Service of Canada and Cosponsors.

Bottema, M., and G. Ph. van Vledder, 2005: Evaluation of the SWAN wave model in slanting fetch conditions. Proc. Fifth Int. Symp. on Ocean Wave Measurement and Analysis, Madrid, Spain, ASCE, CD-ROM, P165.

Bouws, E., H. Günther, W. Rosenthal, and C. L. Vincent, 1985: Similarity of the wind wave spectrum in finite depth water. 1. Spectral form. J. Geophys. Res., 90, 975-986.

Chalikov, D. V., and M. Y. Belevich, 1993: One-dimensional theory of the wave boundary layer. Bound.-Layer Meteor., 63, 65-96.

Chen, G., and S. E. Belcher, 2000: Effects of long waves on windgenerated waves. J. Phys. Oceanogr., 30, 2246-2256.

Dobson, F., W. Perrie, and B. Toulany, 1989: On the deep water fetch laws for wind-generated surface gravity waves. Atmos.Ocean, 27, 210-236.

Donelan, M. A., 1987: The effect of swell on the growth of wind waves. Johns Hopkins APL Technical Digest, Vol. 8, No. 1, $18-23$.

- 2001: A nonlinear dissipation function due to wave breaking. Proc. ECMWF Workshop on Ocean Wave Forecasting, Reading, United Kingdom, ECMWF, 87-94.

— J. Hamilton, and W. H. Hui, 1985: Directional spectra of wind-generated waves. Philos. Trans. Roy. Soc. London, 315A, 509-562.

Drennan, W. M., H. C. Graber, D. Hauser, and C. Quentin, 2003: On the wave age dependence of wind stress over pure wind seas. J. Geophys. Res., 108, 8062, doi:10.1029/2000JC000715.

Forristall, G. Z., and K. C. Ewans, 1998: Worldwide measurement of directional wave spreading. J. Atmos. Oceanic Technol., 15, 440-469.

Gelci, R., H. Cazalé, and J. Vassal, 1957: Prévision de la houle. La méthode des densités spectroangulaires. Bull. Inf. Comité Central Océanogr. Etude Côtes, 9, 416-435.

Graber, H., E. Terray, M. Donelan, W. Drennan, J. V. Leer, and D. Peters, 2000: ASIS-A new air-sea interaction spar buoy: Design and performance at sea. J. Atmos. Oceanic Technol., 17, 708-720.

Hanson, J. L., and O. M. Phillips, 1999: Wind sea growth and dissipation in the open ocean. J. Phys. Oceanogr., 29, 16331648.

Hasselmann, K., 1962: On the non-linear energy transfer in a gravity wave spectrum, part 1: General theory. J. Fluid Mech., 12, 481-501.

_ 1974: On the spectral dissipation of ocean waves due to white capping. Bound.-Layer Meteor., 6, 107-127.

— , and Coauthors, 1973: Measurements of wind-wave growth and swell decay during the Joint North Sea Wave Project. Dtsch. Hydrogr. Z., 8 (Suppl. A), 1-95.

Hasselmann, S., K. Hasselmann, J. Allender, and T. Barnett, 1985: Computation and parameterizations of the nonlinear energy transfer in a gravity-wave spectrum. Part II: Parameterizations of the nonlinear energy transfer for application in wave models. J. Phys. Oceanogr., 15, 1378-1391.

Herbers, T. H. C., and R. T. Guza, 1990: Estimation of directional wave spectra from multicomponent observations. J. Phys. Oceanogr., 20, 1703-1724.

—, M. Orzech, S. Elgar, and R. T. Guza, 2003: Shoaling transformation of wave frequency-directional spectra. J. Geophys. Res., 108, 3013, doi:10.1029/2001JC001304.

Herterich, K., and K. Hasselmann, 1980: A similarity relation for the non-linear energy transfer in a finite-depth gravity-wave spectrum. J. Fluid Mech., 97, 215-224.

Hodur, R. M., 1997: The Naval Research Laboratory's Coupled Ocean/Atmospheric Mesoscale Prediction System (COAMPS). Mon. Wea. Rev., 125, 1414-1430.

Holthuijsen, L. H., 1983: Observations of the directional distribution of ocean wave energy. J. Phys. Oceanogr., 13, 191-207.

Hsu, T.-W., S.-H. Ou, and J.-M. Liau, 2005: Hindcasting nearshore wind waves using a FEM code for SWAN. Coastal Eng., 52, 177-195.

Janssen, P., 1991: Quasi-linear theory of wind wave generation applied to wave forecasting. J. Phys. Oceanogr., 21, 16311642.

, 2004: The Interaction of Ocean Waves and Wind. Cambridge University Press, $300 \mathrm{pp}$.

_ , K. Hasselmann, S. Hasselmann, and G. J. Komen, 1994: Parameterization of source terms and the energy balance in a growing wind sea. Dynamics and Modelling of Ocean Waves, G. J. Komen, et al., Eds., Cambridge University Press, 215238.

- J.-R. Bidlot, S. Abdalla, and H. Hersbach, 2005: Progress in ocean wave forecasting at ECMWF. ECMWF Research Department Tech. Rep. Memo. 478, 29 pp.

Kahma, K. K., 1981: A study of the growth of the wave spectrum with fetch. J. Phys. Oceanogr., 11, 1503-1515.

_ , and C. J. Calkoen, 1992: Reconciling discrepancies in the observed growth of wind-generated waves. J. Phys. Oceanogr., 22, 1389-1405.

Kitaigorodskii, S. A., 1962: Applications of the theory of similarity to the analysis of wind-generated wave motion as a stochastic process. Izv. Geophys. Ser. Acad. Sci., USSR, 1, 105-117.

Komen, G. J., K. Hasselmann, and S. Hasselmann, 1984: On the existence of a fully developed wind-sea spectrum. J. Phys. Oceanogr., 14, 1271-1285.

- L. Cavaleri, M. Donelan, K. Hasselmann, S. Hasselmann, and P. A. E. M. Janssen, 1994: Dynamics and Modelling of Ocean Waves. Cambridge University Press, 554 pp.

Krogstad, H. E., 2002: Second order wave spectra and heave/slope wave measurements. Proc. Fourth Int. Symp. on Ocean Wave Measurement and Analysis, San Francisco, CA, ASCE, 288296.

Kudryavtsev, V. N., and V. K. Makin, 2004: Impact of swell on the marine atmospheric boundary layer. J. Phys. Oceanogr., 34, 934-949.

Kuik, A. J., G. Ph. van Vledder, and L. H. Holthuijsen, 1988: A method for the routine analysis of pitch-and-roll buoy wave data. J. Phys. Oceanogr., 18, 1020-1034.

Long, C. E., and J. Atmadja, 1994: Index and bulk parameters for frequency-direction spectra measured at CERC field research facility, September 1990 to August 1991. U.S. Army Engineer Waterways Experiment Station, Vicksburg, MS, Tech. Rep. CERC-94-5, 245 pp.

Lygre, A., and H. E. Krogstad, 1986: Maximum entropy estimation of the directional distribution in ocean wave spectra. $J$. Phys. Oceanogr., 16, 2052-2060.

Melville, W. K., and P. Matusov, 2002: Distribution of breaking waves at the ocean surface. Nature, 417, 58-63. 
O'Reilly, W. C., T. H. C. Herbers, R. J. Seymour, and R. T. Guza, 1996: A comparison of directional buoy and fixed platform measurements of Pacific swell. J. Atmos. Oceanic Technol., 13, 231-238.

Perrie, W., and B. Toulany, 1990: Fetch relations for windgenerated waves as a function of wind-stress scaling. J. Phys. Oceanogr., 20, 1666-1681.

Pettersson, H., 2004: Wave growth in a narrow bay. Ph.D. thesis, University of Helsinki, $33 \mathrm{pp}$. [Available online at http:// ethesis.helsinki.fi/julkaisut/mat/fysik/vk/pettersson/.]

- , H. C. Graber, D. Hauser, C. Quentin, K. K. Kahma, W. M. Drennan, and M. A. Donelan, 2003: Directional wave measurements from three wave sensors during the FETCH experiment. J. Geophys. Res., 108, 8061, doi:10.1029/ 2001JC001164.

Phillips, O. M., 1985: Spectral and statistical properties of the equilibrium range in wind-generated gravity waves. $J$. Fluid Mech., 156, 505-531.

—_ and M. L. Banner, 1974: Wave breaking in the presence of wind drift and swell. J. Fluid Mech., 66, 625-640.

Pierson, W. J., Jr., and L. Moskowitz, 1964: A proposed spectral form for fully developed wind seas based on the similarity theory of S. A. Kitaigorodskii. J. Geophys. Res., 69, 51815190.

Polnikov, V. G., and L. Farina, 2002: On the problem of optimal approximation of the four-wave kinetic integral. Nonlinear Processes Geophys., 9, 497-512.

Rogers, W. E., 2002: An investigation into sources of error in low frequency energy predictions. Oceanography Division, Naval Research Laboratory, Stennis Space Center, Tech. Rep. Formal Rep. 7320-02-10035, 63 pp.

— , P. A. Hwang, and D. W. Wang, 2003: Investigation of wave growth and decay in the SWAN model: Three regional-scale applications. J. Phys. Oceanogr., 33, 366-389.

Santala, M. J., and E. A. Terray, 1992: A technique for making unbiased estimates of current shear from a wave-follower. Deep-Sea Res., 39, 607-622.

Seymour, R. J., 1977: Estimating wave generation on restricted fetches. J. Waterw. Port Coastal Ocean Eng., 103, 251-264.

Snyder, R. L., F. W. Dobson, J. A. Elliot, and R. B. Long, 1981: Array measurement of atmospheric pressure fluctuations above surface gravity waves. J. Fluid Mech., 102, 1-59.

Tolman, H. L., 2002a: User manual and system documentation of
WAVEWATCH-III version 222. NOAA/NWS/NCEP/ MMAB Tech. Rep. 222, 133 pp.

2002b: Validation of WAVEWATCH-III version 1.15 NOAA/NWS/NCEP/MMAB Tech. Rep. 213, 33 pp.

- and D. Chalikov, 1996: Source terms in a third-generation wind wave model. J. Phys. Oceanogr., 26, 2497-2518.

Tracy, B. A., and D. T. Resio, 1982: Theory and calculation of the nonlinear energy transfer between sea waves in deep water. U.S. Army Engineer Waterways Experiment Station, Vicksburg, MS, Tech. Rep. 11, 54 pp.

van der Westhuysen, A. J., M. Zijlema, and J. A. Battjes, 2007: Saturation-based whitecapping dissipation in SWAN for deep and shallow water. Coastal Eng., 54, 151-170.

van Vledder, G. Ph., 2006: The WRT method for the computation of non-linear four-wave interactions in discrete spectral wave models. Coastal Eng., 53, 223-242.

- and D. P. Hurdle, 2002: Performance of formulations for whitecapping in wave prediction models. Proc. OMAE.02 21st Int. Conf. on Offshore Mechanics and Artic Engineering, Document OMAE2002-28146, Oslo, Norway, AMSE, 1-9.

Walsh, E. J., D. W. Hancock III, D. E. Hines, R. N. Swift, and J. F. Scott, 1989: An observation of the directional wave spectrum evolution from shoreline to fully developed. J. Phys. Oceanogr., 19, 1288-1295.

WAMDI Group, 1988: The WAM model-A third generation ocean wave prediction model. J. Phys. Oceanogr., 18, 17751810.

Watts, K. P., 2003: Fetch-limited wind wave generation on the continental shelf. M.S. thesis, Oceanography Department, Naval Postgraduate School, 93 pp. [Available online at http:// bosun.nps.edu/uhtbin/cgisirsi.exe/1Hphb2sE8E/x/169720010/ 123.]

Webb, D. J., 1978: Nonlinear transfer between sea waves. DeepSea Res., 25, 279-298.

Young, I. R., 1998: An experimental investigation of the role of atmospheric stability in wind wave growth. Coastal Eng., 34, 23-33.

—, and A. V. Babanin, 2006: Spectral distribution of energy dissipation of wind-generated waves due to dominant wave breaking. J. Phys. Oceanogr., 36, 376-394.

— L. L. Verhagen, and M. L. Banner, 1995: A note on the bimodal directional spreading of fetch-limited wind waves. $J$. Geophys. Res., 100, 773-778. 